\title{
La autonomía de las Universidades Nacionales en el Sistema Constitucional argentino. Análisis de las competencias y la jerarquía de las normas en materia de educación superior ${ }^{1}$
}

\author{
The autonomy of National Universities in the \\ Argentine constitutional system. Analysis of \\ competences and the bierarchy of norms in the \\ field of higher education
}

A autonomia das universidades nacionais no sistema constitucional argentino. Análise das competências e a bierarquia das normas no campo do ensino superior

L'autonomie des Universités Nationales dans le Système constitutionnel argentin. Analyse des compétences et de la biérarchie des normes dans le domaine de l'enseignement supérieur 阿根廷宪法体系中国立大学的自治权. 高等教育领域标准的 能力与等级分析

Leandro Abel Martínez ${ }^{2}$ | Universidad de Buenos Aires

Revista Derechos en Acción ISSN 2525-1678/ e-ISSN 2525-1686

Año 4/No 12 Invierno 2019 (21 junio a 20 septiembre), 317-387

DOI: https://doi.org/10.24215/25251678e309

ORCID: https://orcid.org/0000-0003-4594-2328

Recibido: 08/06/2019

Aprobado: 04/08/2019

\footnotetext{
1 La presente contribución se basa en el trabajo final presentado en el marco de la Carrera de Especialización en Derecho Constitucional de la Facultad de Derecho de la Universidad de Buenos Aires. Agradezco a mi amigo y colega Diego A. Dolabjian las discusiones mantenidas durante la elaboración de este trabajo.

2 Abogado (UBA). Especialista en Derecho Constitucional (UBA). Profesor Adjunto (I), en la cátedra del Prof. Dr. Raúl Gustavo Ferreyra, Facultad de Derecho (UBA). Consejero Directivo Facultad de Derecho (UBA) en los períodos: 2016-2018 y 2018-2020. Correo: lamartinez@derecho.uba.ar.
} 
Resumen: La reforma constitucional de 1994 consagró la autonomía y la autarquía de las universidades nacionales en el propio texto de la Constitución Nacional. Antes de la reforma, se sostenía en general que las universidades nacionales gozaban solamente de autarquía. Producto de la reforma de 1994, se plantea el desafío de definir el alcance de la cuestión, toda vez que la constitución no explicita la significación de la autonomía de las universidades nacionales, ni el conjunto de competencias que son resultado de ésta. Sin embargo, el término presenta el problema de los conceptos jurídicos indeterminados, en el sentido de que sus límites no están precisados con exactitud en el enunciado constitucional. A esta dificultad se agrega el hecho normativo de que, al mismo tiempo, el Congreso de la Nación posee la facultad de dictar leyes en materias de educación superior. Frente a este panorama, se puede advertir que la autonomía universitaria debe convivir con las atribuciones del órgano legislativo, y viceversa. En este trabajo me propongo delimitar el ámbito y el rango de las normas legales que corresponde sancionar al Congreso Nacional en virtud de la competencia atribuida por el artículo 75, inciso 19. También indago las normas estatutarias que corresponde dictar a las universidades nacionales en razón de la autonomía reconocida en la misma disposición constitucional, como así también su ubicación en el sistema jurídico

Palabras claves: Autonomía Universitaria. Constitución nacional. Jurisprudencia

Abstract: The 1994 constitutional reform enshrined the autonomy and autarchy of national universities in the text of the National Constitution. Before the reform, it was generally held that national universities enjoyed only autarchy. As a result of the 1994 reform, the challenge is to define the scope of the question, every time the constitution does not make explicit the significance of the autonomy of the national universities, nor the set of competences that result from it. However, the autonomy presents the problem of indeterminate legal concepts, in the sense that their limits are not precisely specified in the constitutional enunciation. To this difficulty is added the normative fact that, at the same time, the Congress of the Nation has the faculty to dictate laws in matters of higher education. Against this backdrop, it can be seen that university autonomy must coexist with the powers of the legislative body, and vice versa. In this work I propose to delimit the scope and range of the legal 
norms that correspond to sanction the National Congress by virtue of the competence attributed by article 75, paragraph 19. I also investigate the statutory norms that correspond to dictate to the national universities due to the autonomy recognized in the constitutional provision itself, as well as its location in the legal system.

Keywords: University Autonomy. National Constitution. Jurisprudence

Resumo: A reforma constitucional de 1994 consagrou a autonomia e a autarquia das universidades nacionais no texto da própria Constituição Nacional. Antes da reforma, se considerava geralmente que as universidades nacionais só gozavam de autarquia. Produto da reforma de 1994, surge o desafio de definir o escopo da questão, toda vez que a constituição não explica o significado da autonomia das universidades nacionais, nem o conjunto de competências que dela resultam. No entanto, o termo apresenta o problema dos conceitos jurídicos indeterminados, no sentido de que seus limites não são especificados exatamente na declaração constitucional. A essa dificuldade adiciona-se o fato normativo de que, ao mesmo tempo, o Congresso Nacional tem as faculdades de promulgar leis em matéria de ensino superior. Frente deste panorama, pode-se notar que a autonomia universitária deve coexistir com os poderes do corpo legislativo e vice-versa. Neste trabalho pretendo delimitar o escopo e a categoria das normas jurídicas que correspondem sancionar ao Congresso Nacional em virtude da competência atribuída pelo artigo 75, parágrafo 19. Investigo também as normas estatutárias que devem ser ditadas pelas universidades nacionais em razão da autonomia reconhecida na mesma disposição constitucional, como assim também sua localização no sistema legal.

Palavras-chave: Autonomia Universitária. Constituição nacional Jurisprudência.

Résumé: La réforme constitutionnelle de 1994 a inscrit l'autonomie et I'autarcie des universités nationales dans le texte de la Constitution Nationale. Avant la réforme, il était généralement admis que les universités nationales ne jouissaient que de l'autarcie. À la suite de la réforme de 1994, le défi consiste à définir la portée de la question, car la Constitution n'explicite pas le cadre de l'autonomie des universités nationales ni l'ensemble des compétences qui en découlent. Toutefois, le terme pose le problème des concepts juridiques indéterminés, en ce 
sens que ses limites ne sont pas spécifiées exactement dans l'énoncé constitutionnel. À cette difficulté s'ajoute le fait normatif que, paraIlèlement, le Congrès national est habilité à adopter des lois en matière d'enseignement supérieur. Dans ce contexte, il convient de noter que l'autonomie des universités doit coexister avec les attributions du corps législatif, et viceversa. Dans le présent document, j'entends délimiter le champ et l'étendue des normes juridiques qui incombent au Congrès national au titre des compétences qui lui sont attribuées par l'article 75, paragraphe 19. J'étudie également les normes statutaires que doivent rédiger les universités nationales en raison de l'autonomie reconnue dans la même disposition constitutionnelle, ainsi que leur place dans le système juridique.

Mot-clés: Autonomie universitaire. Constitution nationale. Jurisprudence

摘要: 1994年的宪法改革在国家宪法本身的文本中规定了国立大学 的自治和专制. 在改革之前, 人们普遍认为国立大学只享有专制. 由 于1994年的改革, 挑战在于确定问题的范围, 因为宪法没有解释国 立大学自治的重要性, 也没有解释由此产生的一系列能力. 然而, 该 术语提出了不确定的法律概念问题，因为它的限制没有在宪法声明 中明确规定. 对于这一困难, 增加了一个规范性事实, 即同时国民议 会有权在高等教育问题上制定法律. 在此背景下, 可以注意到大学自 治必须与立法机构的权力共存, 反之亦然. 在本文中, 我打算界定与 根据第75条第19款所赋予的权限制裁国民议会相对应的法律规范 的范围和范围. 我还调查了必须由国家大学规定的法定规范. 自治 权在同一宪法条款中得到承认, 以及在法律制度中的地位

关键字: 大学自治, 国家宪法, 法理学

\section{Introducción}

\section{I.1. Tema y breve marco teórico}

La reforma constitucional de 1994 consagró la autonomía y la autarquía de las universidades nacionales en el propio texto de la Constitución Nacional (en adelante CN). Concretamente, tales atributos se introdujeron en el artículo 75, inciso 19, párrafo 3. Mediante este enunciado, conocido como "cláusula 
del nuevo progreso", se encomienda al Congreso Nacional "Sancionar leyes de organización y de base de la educación (...) que garanticen los principios de gratuidad y equidad de la educación pública estatal y la autonomía y autarquía de las universidades nacionales".

Antes de la reforma, por un lado, se sostenía en general que las universidades nacionales gozaban solamente de autarquía, es decir, la facultad de regularse a sí mismas en sus aspectos administrativos, económicos y financieros. Por otro lado, tanto la doctrina como la jurisprudencia les reconocían una autonomía sólo limitada a los aspectos elementales del quehacer académico. De este modo, se presentaba una mirada acotada del concepto de "autonomía".

Producto de la reforma de 1994, se plantea el desafío de definir el alcance de la cuestión, toda vez que la $\mathrm{CN}$ no explicita la significación de la autonomía de las universidades nacionales, ni el conjunto de competencias que son resultado de ésta. Básicamente, se entiende que la autonomía supone la atribución de un ente para darse sus propias normas y órganos de gobierno. Sin embargo, el término presenta el problema de los conceptos jurídicos indeterminados, en el sentido de que sus límites no están precisados con exactitud en el enunciado constitucional. A esta dificultad se agrega el hecho normativo de que, al mismo tiempo, el Congreso de la Nación posee la facultad de dictar leyes en materias de educación superior. Ello surge del citado artículo 75, tanto del ya citado inciso 19 como del 18, que lo faculta a dictar "planes de instrucción general y universitaria”. Frente a este panorama, se puede advertir que la autonomía universitaria debe convivir con las atribuciones del órgano legislativo, y viceversa.

\section{I.2. Hipótesis y objetivos}

En este trabajo me propongo delimitar el ámbito y el rango de las normas legales que corresponde sancionar al Congreso Nacional en virtud de la competencia atribuida por el artículo 
75, inciso 19. También indago las normas estatutarias que corresponde dictar a las universidades nacionales en razón de la autonomía reconocida en la misma disposición constitucional, como así también su ubicación en el sistema jurídico.

Los objetivos son los siguientes:

1) Describir el marco constitucional y legal de las universidades públicas.

2) Delimitar las competencias de las universidades nacionales y del Congreso de la Nación en materia de educación superior.

3) Establecer el nivel de jerarquía de las normas que son creadas en ejercicio de las competencias referidas en el punto anterior.

Sostengo que el Congreso puede definir el modelo educativo universitario y, por lo tanto, dictar -por ejemplo- la Ley de Educación Superior (en adelante LES), pero la autonomía universitaria consagrada por la $\mathrm{CN}$ genera un núcleo irreductible sobre el cual el Congreso no puede intervenir. En lo relativo a esa esfera propia de competencias, los estatutos universitarios sólo deben acatamiento a la Constitución y a los tratados internacionales con jerarquía constitucional. A esto se suman lo que podrían denominarse "competencias concurrentes" entre el Congreso y las universidades públicas.

Estas últimas surgen de la conjugación de la autonomía universitaria con la potestad del Congreso de sancionar leyes de organización y de base de la educación y dictar planes universitarios. La categoría concurrente es utilizada con frecuencia por la doctrina constitucional para explicar algunas tareas que deben realizar de manera conjunta los poderes federales y provinciales. Independientemente de la utilización teórica del término "competencia concurrente"3, aquí entiendo que por mandato constitucional hay ciertos temas en los cuales

3 Considero que sería más adecuado hablar de "competencias complementarias" para explicar este tipo de relaciones entre el Congreso y las universidades. 
el Congreso establece el marco general de políticas públicas universitarias y las universidades nacionales se desenvuelven o ejercen su autonomía respetando esos parámetros, pero con un margen suficiente para desarrollar políticas específicas.

En resumen, existen tres esferas de competencias en materia de educación superior: 1) competencias exclusivas del Congreso; 2) competencias exclusivas de las universidades públicas ${ }^{4}, y$ 3) competencias concurrentes del Congreso y las universidades públicas. En el primer supuesto, se trata de atribuciones que sólo puede ejercer el Congreso, como por ejemplo la creación de universidades nacionales. En el segundo caso, son potestades derivadas de la autonomía constitucional, que se vinculan con la esencia del quehacer de las universidades y que, por lo tanto, no pueden ser alcanzadas por la regulación del Congreso, como el régimen de permanencia docente y las causales de juicio académico de los profesores. Por último, existen materias en las cuales el Congreso define el marco general y las universidades nacionales desarrollan la regulación posterior, por ejemplo, la Ley de Educación Superior determina que en el cogobierno los profesores tienen una mayoría que no puede ser inferior al $50 \%$ y deja librado a cada universidad el grado de participación de estudiantes, graduados y no docentes.

A lo largo de este trabajo, afirmo que el principio de competencia determina diferentes órdenes de jerarquías. Por esta razón, en cada uno de los supuestos enunciados se configuran distintos campos normativos. A raíz de ello, no se puede pregonar la existencia de un régimen normativo universal y aplicable de manera automática a la multiplicidad de temas. Cuando el Congreso ejerce competencias exclusivas, la ley prevalece sobre los estatutos de las universidades. En cambio, ante la utilización de competencias exclusivas de las universidades públicas, los estatutos se posicionan por encima de las leyes en caso

\footnotetext{
4 Respecto a esta categoría entiendo que existen competencias exclusivas de las universidades públicas en dos sentidos: a) competencias explicitadas por la LES, y b) competencias implícitas que se derivan de la autonomía constitucional y que no están enunciadas en la LES.
} 
de contradicciones normativas. Frente al dictado de normas de base por parte del Congreso, los estatutos deben prestar conformidad con ellas, ya que aquí la tarea es conjunta, pero es el órgano legislativo el que fija el marco general y las universidades, el específico. De lo expuesto se puede advertir que la competencia determina el escalafón normativo aplicable para cada caso. El desafío es construir un modelo analítico que permita resolver la multiplicidad de casos.

\section{3. Recorrido}

En primer lugar, describo las reglas básicas de la $\mathrm{CN}$ en función de las que se estructura la posición de los distintos tipos de normas que integran el sistema jurídico argentino, ya que de acuerdo al entramado constitucional las normas tienen asignado un valor. Sin embargo, el orden jurídico no se presenta en todos los casos de la misma manera. Esto responde a que la $\mathrm{CN}$ distribuye tareas entre los distintos poderes y entes estatales. Por lo tanto, para explicar el fenómeno jurídico constitucional es necesario distinguir entre un criterio de prelación formal y otro de competencia material. El primer parámetro se concentra en la jerarquía de las normas, haciendo prevalecer, en caso de conflicto, a las superiores por sobre las inferiores. El segundo se focaliza en la determinación de la titularidad de la atribución normativa, con prescindencia del valor de las disposiciones.

En segundo lugar, analizo el significado y el alcance de la autonomía de las universidades nacionales, a partir de su proclamación inaugural en los postulados reformistas de 1918 y su posterior consagración constitucional en 1994. El propósito es determinar la correspondiente competencia normativa de las universidades y la jerarquía de sus estatutos. Teniendo en cuenta que la autonomía implica la asignación constitucional de competencias, una labor consiste en desentrañar el campo de actuación de las universidades públicas y otra distinta reside en identificar el valor de las normas derivadas del ejercicio 
de esta actividad. En suma, los interrogantes a develar son los siguientes: ¿qué competencia para obrar tienen las universidades? y ¿qué jerarquía poseen las normas creadas por éstas como consecuencia de la competencia atribuida?

En tercer lugar, examino algunas de las relaciones paradigmáticas que pueden darse entre el ámbito de las leyes estatales y el campo de los estatutos universitarios. En tal sentido, por un lado, me interesa identificar una situación de incompatibilidad entre una ley del Congreso Nacional y el Estatuto de la Universidad de Buenos Aires (en adelante UBA). En concreto, abordo el conflicto entre la Ley 26.508 -"Personal docente de las universidades públicas nacionales. Jubilaciones y pensiones. Beneficios"- y el artículo 51 del Estatuto de la UBA, que regula el régimen de permanencia de los profesores. Por otro lado, analizo una situación de compatibilidad entre ambos terrenos normativos: puntualmente, la aplicación a las universidades del régimen especial de concesiones para personas con discapacidad, regulado por la Ley 24.308, modificatoria del Decreto-Ley 22.431.

A partir de tal desarrollo, procuro alcanzar una interpretación del artículo 75, inciso 19, párrafo 3, que armonice adecuadamente las dos esferas a la que alude la disposición constitucional (competencias del Congreso Nacional y autonomía de las universidades) y los dos tipos de normas que son su resultado directo (leyes estatales y estatutos universitarios), en línea con los principios proclamados en la histórica gesta reformista de 1918. En definitiva, el presente trabajo procura indagar la dimensión de la autonomía reconocida por la CN a las universidades nacionales. El primer objetivo es dilucidar qué ámbitos corresponden a la regulación de los estatutos universitarios y qué campos, a la reglamentación de las leyes estatales. El segundo, establecer el nivel de jerarquía de las normas generadas en ejercicio de la competencia atribuida por la $\mathrm{CN}$ al Congreso y a las universidades públicas en materia de educación superior. 


\section{Competencia y jerarquía en el Sistema Constitucional Argentino}

La CN define y ordena la posición de los distintos tipos de normas que integran el sistema jurídico argentino, con base en un criterio de competencia material y un criterio de jerarquía o de prelación formal. La competencia, de acuerdo con Carlos F. Balbín, es "el conjunto de potestades que surge del ordenamiento jurídico, esto es, la capacidad o aptitud de los poderes públicos para obrar y cumplir así sus cometidos"5. En cambio, la jerarquía, según Carlos S. Nino, consiste en que "las cadenas de validez formadas sobre la base de las normas que autorizan la creación de otras nos ofrecen una ordenación jerárquica de las normas (...) Se puede decir que una norma es superior a otra cuando, de haber conflicto entre ellas, se consideraría válida la primera, no la segunda" 6 .

El artículo 31, CN, en conjunción con otras disposiciones del texto constitucional -según se explica más adelante-, consagra el principio de supremacía de la ley fundamental. Tal primacía de la $\mathrm{CN}$ responde a que, según explica Raúl Gustavo Ferreyra, a la constitución se la “... puede definir como un sistema de normas abiertas que expresan el principio de la soberanía de los ciudadanos que integran el pueblo y que concretiza en su texto la correspondiente carta de navegación político-institucional. No existe norma positiva por encima de la constitución". ${ }^{7}$ En consecuencia, como afirma Alberto R. Dalla Vía, "la supremacía surge, entonces, como una cuestión lógica"8.

Desde tal posición, la $\mathrm{CN}$, en cuanto norma suprema del ordenamiento jurídico, atribuye competencia normativa a los poderes, órganos y entes por ella creados. A su vez, establece

\footnotetext{
5 Balbín, Carlos F., Curso de Derecho Administrativo, Buenos Aires, La Ley, 2007, p. 554.

6 Nino, Carlos Santiago, Introducción al análisis del derecho, Buenos Aires, Astrea, 1998, p. 153.

7 Ferreyra, Raúl Gustavo, Fundamentos Constitucionales, Buenos Aires, Ediar, 2013, pp. 212 y ss.

8 Dalla Vía, Alberto R., Manual de Derecho Constitucional, Buenos Aires, Abeledo Perrot, 2009, p. 74
} 
el procedimiento que éstos deben respetar para dar nacimiento a las normas que son de su dominio. La norma fundamental estructura un orden jerárquico, toda vez que le confiere un valor diferenciado a cada norma jurídica creada de conformidad con los procedimientos constitucionales.

En cuanto a la distinción entre el principio de competencia y el de jerarquía, Balbín explica que “... el criterio más simple y recogido en nuestro ordenamiento jurídico positivo es el criterio jerárquico, es decir, el juego de grados superiores e inferiores entre normas jurídicas..."9. Así, frente a una contradicción entre dos normas de distinta jerarquía, el conflicto se resuelve haciendo prevalecer la de mayor rango. Con relación al principio de competencia, este autor distingue entre el régimen del Estado federal y el de las provincias, señalando que no deben confundirse los marcos jurídicos materiales de ambos.

El aspecto aquí jurídicamente relevante es el deslinde material y en este primer paso es irrelevante el criterio jerárquico entre normas, es decir, el rango de las normas. Una vez definido el campo material de uno u otro, prevalece el ordenamiento jurídico competente por las materias, más allá del rango de las normas. El segundo paso, y ya ubicados en el campo material competente, [es] el armado del rompecabezas entre normas en el interior de ese campo y según el principio jerárquico. ${ }^{10}$

En resumen, competencia y jerarquía son conceptos distintos, que explican distintas situaciones entre normas jurídicas de un mismo sistema. En algunos casos, puede presentarse una relación de jerarquía entre normas; pero en otros, ello no ocurre, ya que lo que interesa es la determinación del sujeto atribuido de la potestad de obrar en determinada materia. Entonces, en este último supuesto, las controversias se resuelven identificando en forma concreta el poder, órgano o ente competente, y no atendiendo simplemente a la jerarquía normativa en abstracto.

\footnotetext{
9 Balbín, ob. cit., pp. 246 y ss.

10 Ibíd.
} 


\section{1. La distribución de las competencias normativas en la Constitución Nacional}

La $\mathrm{CN}$, desde su redacción original, distribuye las competencias normativas entre el Estado federal, las provincias y los municipios. Tal afirmación surge como resultado del artículo 1, que consagra el federalismo como forma de Estado. Por su parte, el artículo 5 otorga autonomía a las provincias estableciendo sus competencias para crear normas según el tipo de materias. De esta forma, se determina una convivencia entre los diferentes niveles de gobierno.

Las reglas generales de distribución de competencias entre los poderes federales y locales se encuentran reguladas en los artículos 121 y 126. Básicamente, los entes locales conservan todo el poder no delegado por la $\mathrm{CN}$ al gobierno federal. Por ende, las provincias tienen poderes reservados y el gobierno federal posee poderes delegados. Sin embargo, esta división no termina de explicar el sistema de reparto. Cabe aclarar que la CN reformada en 1994 mantuvo este esquema básico, pero agregó otros sujetos con atribuciones normativas: la Ciudad Autónoma de Buenos Aires y las Universidades Nacionales, entre otros entes autónomos ${ }^{11}$.

Germán J. Bidart Campos explica que en el sistema de distribución se pueden distinguir tipos de competencia diversos: “... a) competencias exclusivas del Estado federal; b) competencias exclusivas de las provincias; c) competencias concurrentes; d) competencias excepcionales del Estado federal y de las provincias; e) competencias compartidas por el Estado federal y las provincias"12. Dada esta clasificación y, en particular las tres primeras categorías, ejemplifico la cuestión en torno a las competencias normativas en razón de la materia.

\footnotetext{
11 Este último tópico es retomado en el capítulo 2.

12 Bidart Campos, Germán J., Manual de la Constitución Reformada, T. 1, Buenos Aires, Ediar, 1996, p. 443.
} 
En lo que respecta a las competencias exclusivas del Estado federal, se puede enunciar que el Congreso Nacional tiene la atribución de dictar la legislación federal y la común ${ }^{14}$ (conf. art. 75 , inc. 12, CN). En lo atinente a las competencias exclusivas de las provincias, conservan la facultad de dictar sus leyes procesales (conf. art. 5, CN). Acerca de las competencias concurrentes, es ilustrativa la cuestión ambiental, dado que el gobierno federal establece la legislación que debe contener presupuestos mínimos de protección. Por lo tanto, la Nación y las provincias están obligadas a ordenar sus respectivas legislaciones en el mismo sentido (conf. art. 41, CN).

Ahora bien, frente a este panorama, es necesario explicar las distintas relaciones entre las normas jurídicas creadas por los poderes federales y aquellas que surjan de las autoridades provinciales, pues resulta evidente que tanto la Nación como las provincias deben legislar en el marco de sus respectivas competencias. Para resolver estas cuestiones existen pautas o criterios de interpretación que ayudan a explicar o dirimir potenciales conflictos: precisamente, los principios de jerarquía y de competencia. Si bien cada uno responde a su respectiva mecánica, cuando se presentan problemas de interpretación o cuando se requiere dar claridad y orden en la materia, debe establecerse el contenido y el alcance de cada uno.

Interpreto que frente a atribuciones exclusivas, ya sean del gobierno federal o del provincial, lo que explica las relaciones entre ambos es el criterio de competencia. Piénsese, por ejemplo, en un proceso penal en el cual se investiga la comisión de un delito común, sustanciado en el ámbito de una provincia.

\footnotetext{
13 Excluyo del análisis las últimas dos categorías dado que no son competencias de utilización frecuente.

14 En este punto cabe aludir a la distinción entre el derecho federal y el derecho común, que es relevante ya que condiciona la actuación de la justicia federal o local, según corresponda. Sin embargo, no existe una relación de jerarquía entre el derecho federal y el derecho común, por lo que ambos se encuentran en un pie de igualdad. La diferencia radica en que regulan materias distintas y que los tribunales competentes no son los mismos.
} 
El delito está tipificado en el Código Penal dictado por el Congreso Nacional (potestad exclusiva federal); en cambio, las reglas procesales para llevar adelante el enjuiciamiento se encuentran definidas en la ley adjetiva dictada por la legislatura local (potestad exclusiva provincial).

Entre estos campos normativos, en principio, no debería existir conflicto, ni relación de subordinación entre el derecho común y el derecho provincial, ya que nos encontramos ante el ejercicio de competencias exclusivas y que regulan materias distintas. Desde luego, el límite del ejercicio competencial es la adecuación con la CN y los tratados con jerarquía constitucional. En atención a ello, si se suscitaran colisiones normativas entre la esfera federal y la provincial, la causa obedecería a que hubo una norma que se inmiscuyó en el ámbito material de competencias de la otra. Entonces, el conflicto no se resolvería mediante la aplicación del principio jerárquico, sino verificando qué orden es competente en la regulación. Por el contrario, este argumento no es aplicable en materias en las que las potestades son concurrentes. Tal como se ejemplificó con la cuestión ambiental, las normas locales deben respetar los presupuestos de base fijados por el Congreso Nacional, por lo que es el criterio jerárquico el que traduce esta vinculación.

Por otra parte, la CN también distribuye competencias entre el Congreso y las universidades nacionales, razón por la cual pueden darse distintos tipos de relaciones normativas. En algunos casos, es el principio jerárquico el que explica esas conexiones y, en otros, el de jerarquía. En este trabajo se argumenta que pueden identificarse tres tipos de competencias: exclusivas del Congreso, exclusivas de las universidades y concurrentes. Las potestades exclusivas implican una relación directa, ya sea de la ley con la CN, o de los estatutos con la CN. En cambio, las facultades concurrentes traen aparejado un trabajo conjunto y escalonado entre Congreso y las universidades públicas. De alguna manera, este último tipo de competencia se asemeja a la cuestión ambiental antes descripta, toda vez que el Congreso 
establece los presupuestos mínimos ambientales y las provincias desarrollan la legislación específica respetando esa normativa.

En definitiva, las universidades nacionales tienen reconocimiento de su autonomía por parte de la $\mathrm{CN}$, pero ella no indica expresamente cuál es el ámbito de la competencia material correspondiente a los estatutos universitarios que pueden dictarse. Esto se vincula con las leyes de base y organización de la educación que dicte el Congreso Nacional y que, a su vez, garanticen la autonomía universitaria. De este modo, el principio de autonomía universitaria opera de manera concurrente con la voluntad del legislador nacional. Sin embargo, esa autonomía tiene un reducto propio, que no puede ser alcanzado por las leyes estatales.

\section{2. El orden de las jerarquías normativas en la Constitución Nacional}

Desde sus orígenes, la CN estructura un orden entre las distintas normas del sistema jurídico. El artículo 31 determina que "Esta Constitución, las leyes de la Nación que en su consecuencia se dicten por el Congreso y los tratados con las potencias extranjeras son la ley suprema de la Nación; y las autoridades de cada provincia están obligadas a conformarse a ella...”. El artículo 27 establece que "El Gobierno federal está obligado a afianzar sus relaciones de paz y comercio con las potencias extranjeras por medio de tratados que estén en conformidad con los principios de derecho público establecidos en esta Constitución". El artículo 28 dispone que "Los principios, garantías y derechos reconocidos en los anteriores artículos, no podrán ser alterados por las leyes que reglamenten su ejercicio". Por último, el artículo 99, inciso 2 (antiguo art. 86, inc. 2) dispone que el Presidente "Expide las instrucciones y reglamentos que sean necesarios para la ejecución de las leyes de la Nación, cuidando de no alterar su espíritu con excepciones reglamentarias".

Del juego armónico de tales normas surgía, por un lado, la prevalencia del derecho federal por sobre el derecho emanado 
de las provincias; y, por otro, la supremacía de la Constitución por sobre todas las demás normas y la subordinación de los decretos respecto de las leyes, pero restaba definir la ordenación entre las leyes y los tratados ${ }^{15}$. La Constitución reformada en 1994 mantuvo este esquema básico, aunque agregó otras disposiciones que reconfiguraron el orden jerárquico del derecho federal.

Ello sucedió con la introducción del artículo 75 -en sus incs. 22 y $24-$ y de los artículos 76 y 99, inciso 3.

Art. 75, inc. 22, CN: Los tratados y concordatos tienen jerarquía superior a las leyes. La Declaración Americana de los Derechos y Deberes del Hombre; la Declaración Universal de Derechos Humanos; la Convención Americana sobre Derechos Humanos; el Pacto Internacional de Derechos Económicos, Sociales y Culturales; el Pacto Internacional de Derechos Civiles y Políticos y su Protocolo Facultativo; la Convención sobre la Prevención y la Sanción del Delito de Genocidio; la Convención Internacional sobre la Eliminación de todas las Formas de Discriminación Racial; la Convención sobre la Eliminación de todas las Formas de Discriminación contra la Mujer; la Convención contra la Tortura y otros Tratos o Penas Crueles, Inhumanos o Degradantes; la Convención sobre los Derechos del Niño; en las condiciones de su vigencia, tienen jerarquía constitucional, no derogan artículo alguno de la primera parte de esta Constitución y deben entenderse complementarios de los derechos y garantías por ella reconocidos. Sólo podrán ser denunciados, en su caso, por el Poder Ejecutivo Nacional, previa aprobación de las dos terceras partes de la totalidad

\footnotetext{
15 Bajo tal sistema constitucional, no existía un consenso en la doctrina ni en la jurisprudencia en torno a la ubicación jerárquica de las leyes y los tratados. En el caso "S.A. Martín y Cía. Ltda. v. Nación Argentina" (Fallos: 257: 99), de 1963, la CSJN estableció la paridad jerárquica entre las leyes y los tratados, previendo como solución, ante una colisión normativa, la aplicación de los principios generales del derecho. Luego, en el caso “Ekmekdjián, Miguel Ángel c. Sofovich, Gerardo y otros" (Fallos: 315: 1492), de 1992, la CSJN consagró la primacía de los tratados por sobre las leyes del Congreso.
} 
de los miembros de cada Cámara. Los demás tratados y convenciones sobre derechos humanos, luego de ser aprobados por el Congreso, requerirán del voto de las dos terceras partes de la totalidad de los miembros de cada Cámara para gozar de la jerarquía constitucional.

Esta disposición trajo dos novedades: la primera es la superioridad de los tratados por sobre las leyes; la segunda, el otorgamiento de jerarquía constitucional -en las condiciones de su vigencia- a las normas del derecho internacional de los derechos humanos enumeradas en tal inciso. Asimismo, el poder constituyente reformador -en el párrafo tercero del inc. 22- generó un dispositivo para que uno de los poderes constituidos, más precisamente el Congreso Nacional, pueda asignarle jerarquía constitucional a otros tratados y convenciones sobre derechos humanos, en tanto y en cuanto lo haga con el voto de las dos terceras partes de la totalidad de los miembros de cada Cámara ${ }^{16}$.

El artículo 75, inciso 24, faculta al Congreso Nacional para "Aprobar tratados de integración que deleguen competencias y jurisdicción a organizaciones supraestatales en condiciones de reciprocidad e igualdad, y que respeten el orden democrático y los derechos humanos. Las normas dictadas en su consecuencia tienen jerarquía superior a las leyes”. De este modo, se establece que las normas dictadas por organizaciones supraestatales, como consecuencia de las competencias delegadas por tratados de integración, tienen jerarquía superior a las leyes.

Sobre la base de lo expuesto, se puede resumir que a raíz de la reforma constitucional conviven instrumentos internacionales con distinta jerarquía: algunos al mismo nivel que la Constitución y otros por debajo, pero en cualquier caso superiores a las leyes.

16 Por obra de este mecanismo, luego de la reforma de 1994 se otorgó jerarquía constitucional a tres instrumentos: la Convención Interamericana sobre Desaparición Forzada de Personas (1997), la Convención Internacional sobre la Imprescriptibilidad de Crímenes de Guerra y de Lesa Humanidad (2003) y la Convención sobre los Derechos de las Personas con Discapacidad (2014). 
Asimismo, se regularon las potestades reglamentarias del Poder Ejecutivo, al configurarse un régimen constitucional tanto para los decretos delegados como para los de necesidad y urgencia.

Art. 76, CN: Se prohíbe la delegación legislativa en el Poder Ejecutivo, salvo en materias determinadas de administración o de emergencia pública, con plazo fijado para su ejercicio y dentro de las bases de la delegación que el Congreso establezca. La caducidad resultante del transcurso del plazo previsto en el párrafo anterior no importará revisión de las relaciones jurídicas nacidas al amparo de las normas dictadas en consecuencia de la delegación legislativa.

Art. 99, inc. 3, CN: El Poder Ejecutivo no podrá en ningún caso bajo pena de nulidad absoluta e insanable, emitir disposiciones de carácter legislativo. Solamente cuando circunstancias excepcionales hicieran imposible seguir los trámites ordinarios previstos por esta Constitución para la sanción de las leyes, y no se trate de normas que regulen materia penal, tributaria, electoral o de régimen de los partidos políticos, podrá dictar decretos por razones de necesidad y urgencia, los que serán decididos en acuerdo general de ministros que deberán refrendarlos, conjuntamente con el jefe de gabinete de ministros. El jefe de gabinete de ministros personalmente y dentro de los diez días someterá la medida a consideración de la Comisión Bicameral Permanente, cuya composición deberá respetar la proporción de las representaciones políticas de cada Cámara. Esta comisión elevará su despacho en un plazo de diez días al plenario de cada Cámara para su expreso tratamiento, el que de inmediato considerarán las Cámaras. Una ley especial sancionada con la mayoría absoluta de la totalidad de los miembros de cada Cámara regulará el trámite y los alcances de la intervención del Congreso.

$\mathrm{Al}$ respecto, el artículo 76 permite que el Congreso Nacional delegue en el Poder Ejecutivo la posibilidad de dictar normas en determinadas materias de administración o de emergencia 
pública, por un plazo fijado. También se le concede, conforme al artículo 99, inciso 3, la atribución de emitir decretos de necesidad y urgencia en ciertas condiciones. Este tipo de decretos, desde mi punto de vista, se ubican en el mismo nivel que las leyes, toda vez que en un caso el Presidente emite disposiciones materialmente legislativas por voluntad del Congreso Nacional $\mathrm{y}$, en el otro, por iniciativa propia. ${ }^{17}$

Para finalizar, cabe esquematizar parcialmente los escalones normativos, de acuerdo al principio jerárquico, de la siguiente forma:

1. La CN / Los tratados de derechos humanos con jerarquía constitucional.

2. El resto de los tratados internacionales.

3. Las normas dictadas por los organismos supranacionales de integración.

4. Las leyes del Congreso Nacional / Los decretos de necesidad y urgencia / Los decretos de delegación legislativa.

5. Los reglamentos.

Hasta aquí he reseñado las modificaciones más relevantes que trajo la reforma de 1994 en la reestructuración del orden de jerarquía de las diferentes normas que pueden crear los poderes estatales. Sin embargo, resta indagar cuál es la ubicación de las normas que están habilitadas a formular otros entes constitucionales. Dentro de éstos, se encuentran las universidades nacionales. Si bien la CN reformada les reconoce autonomía, no señala explícitamente cuál es el rango de jerarquía formal que corresponde a los estatutos universitarios que pueden dictarse en función de aquella autonomía. Cabe aclarar que las normas universitarias no tienen el mismo rango en todos los casos.

El principio de competencia determina la jerarquía de las normas dictadas por el Congreso y las universidades nacionales.

17 En la doctrina no existe consenso sobre el rango jerárquico de los decretos delegados y los de delegación legislativa. Algunos autores entienden que se colocan en el mismo nivel que las leyes y otros, por debajo. 
Tomando la clasificación anunciada precedentemente, en torno a los tres tipos de competencia que pueden darse en materia de educación superior, entiendo que se configuran tres órdenes jurídicos diferenciados. En el primer escenario, si el Congreso dicta una ley en ejercicio de competencias exclusivas, ésta no puede ser contradecida por los estatutos. En el segundo, si las universidades públicas regulan en sus estatutos temas de su competencia exclusiva, éstos no pueden ser invadidos por la ley. En el tercero, si la materia es concurrente, el Congreso dicta el marco general y las universidades, el específico, respetando las estipulaciones de la legislación. En conclusión, el orden jurídico respectivo se conforma según el tipo de competencia ejercitada

\section{La autonomía de las Universidades Nacionales en el Sistema Constitucional Argentino}

La reforma constitucional de 1994 confirió autarquía y autonomía a las universidades nacionales. De este modo quedó superada la discusión en torno al estatus de las instituciones públicas universitarias. El modelo receptado por la última asamblea constituyente tuvo como hito paradigmático los sucesos de la Reforma Universitaria de 1918. Desde ese entonces se fueron perfilando, poco a poco, los rasgos distintivos de las universidades públicas nacionales. En la actualidad, las reivindicaciones de 1918 se ven plasmadas, con matices, en los estatutos de las universidades públicas de todo el territorio de la Nación. Los estatutos son dictados por las asambleas de cada universidad. En este órgano se expresa el principio democrático del cogobierno, es decir, la participación de todos los componentes de la vida universitaria: estudiantes, graduados, profesores y, en algunos casos, trabajadores no docentes.

El dictado de los estatutos universitarios constituye la máxima manifestación normativa de la autonomía constitucional, toda vez que ellos expresan la capacidad de las universidades públicas de darse sus propias normas en los aspectos fundamentales del quehacer universitario. De allí que éstos sean la norma de 
mayor jerarquía de las instituciones universitarias. Sin embargo, la potestad de autonormarse se encuentra precisada por la Ley de Educación Superior, que define -entre otras cuestiones- el alcance de la autonomía constitucional.

Ahora bien, de acuerdo a la materia, pueden darse distintas relaciones entre los estatutos de las universidades y las leyes del Congreso dictadas en materia de educación superior. Esto supone dos planos de análisis: la competencia para dictar normas y la jerarquía de ellas.

\section{1. Los principios de la Reforma Universitaria de 1918}

El legado de la Reforma Universitaria de 1918 determinó el devenir de la educación pública superior. La gesta reformista dio lugar a un conjunto de principios que fueron reconfigurando el modelo de universidad pública, gratuita y autónoma de nuestros días. Entre ellos se destacan, principalmente, la autonomía, el cogobierno, la periodicidad en las cátedras, los concursos públicos, la docencia libre, el mandato limitado de las autoridades, la investigación y la extensión universitaria.

Con relación a la influencia del reformismo universitario de 1918 en la reforma constitucional de 1994, Gonzalo Álvarez y Sebastián Scioscioli postulan que el texto constitucional tomó el legado reformista:

Lo que hizo el constituyente fue receptar el modelo universitario histórico de la Argentina, con universidades con competencias para autonormarse y gobernarse conforme estas normas, la potestad de definir los alcances de las funciones de docencia, investigación y extensión y la potestad de administrar sus recursos, sin injerencias del Poder Ejecutivo y el Poder Legislativo nacional, y siendo sus actos únicamente revisables por el Poder Judicial. ${ }^{18}$

\footnotetext{
18 Álvarez, Gonzalo y Sciosciolı, Sebastián, "Las bases constitucionales de la educación argentina a la luz de la reforma constitucional de 1994", en Bernal, Marcelo; Pizzolo, Calogero y RossetTı, Andrés (coord.), ¡Que veinte años no es nada!: Un análisis crítico a veinte años de la reforma constitucional de 1994 en Argentina, Buenos Aires, Eudeba, 2015, p. 249.
} 
En igual sentido, Atilio Aníbal Alterini entiende que la reforma constitucional de 1994 también adoptó el legado reformista al consagrar la autonomía universitaria:

... la autonomía de las universidades públicas queda sujeta a la base histórica de los principios reformistas, pues cuando la Constitución se refiere a las universidades públicas lo hace a universidades concebidas a ese modelo. Un principio es la consagración a la docencia, a la investigación y a la extensión, con afirmación expresa de la función social de la universidad. Otro es el de cogobierno: los claustros que componen la universidad deben participar en los órganos colegiados de gobierno institucional asignando al claustro de profesores regulares el carácter de principal núcleo de la enseñanza y la investigación. Otro es el de periodicidad de los cargos docentes y su provisión y renovación por medio de concursos públicos de antecedentes y oposición. ${ }^{19}$

Adolfo Stubrin sintetiza el espíritu de la Reforma Universitaria y lo vincula con el principio republicano de gobierno y su inserción en el marco de un Estado federal.

En la médula de la configuración están la autonomía, el cogobierno y los concursos públicos -es decir: un mecanismo efectivo de articulación entre los grupos académicos-, las conducciones institucionales y los elencos gubernamentales, canalizados a través de la participación política interna de docentes y estudiantes. La confianza del gobierno federal en esas micro repúblicas de ciudadanos universitarios a quienes delega importantes potestades públicas es el cemento básico. ${ }^{20}$

\footnotetext{
19 Alterinı, Atilio Aníbal, La universidad pública en un proyecto de nación, Buenos Aires, La Ley, 2005, p. 114.

20 StuBRin, Adolfo, "La Reforma de 1918: el hecho crucial para la configuración universitaria de la Argentina", en AlBornoz, Mario y CRespo, Manuel (comp. ), La universidad reformada: hacia el centenario de la reforma universitaria de 1918, Ciudad Autónoma de Buenos Aires, Eudeba, 2017, p. 68.
} 
De igual modo, Alejandro Finocchiaro, al analizar el impacto reformista en los estatutos, concluye:

Entre los cambios más significativos pueden contarse la periodicidad en las cátedras y en los mandatos de las autoridades, la prohibición de superponer cargos, la incompatibilidad entre cargos directivos y empleos rentados, la posibilidad de que todos los profesores y no solo los titulares pudiesen participar del gobierno, la docencia libre y la extensión universitaria. ${ }^{21}$

Por su parte, la Corte Suprema de Justicia de la Nación (en adelante CSJN), en el caso "Barsanti, Agustina c/UBA (Universidad de Buenos Aires) Resolución 2314/95"22 (1998), reconoció la influencia de la reforma universitaria en el estatus constitucional de las universidades:

La expresión "autonomía universitaria" evoca inconfundiblemente cuestiones largamente debatidas por la sociedad toda, que por otra parte poseen orígenes seculares, en el peculiar status que se les reconoció a las universidades en la historia de occidente, y más próximamente, a partir del movimiento de la "reforma universitaria", que nació en nuestro país y alcanzó amplia trascendencia en otros. (Disidencia del Dr. Carlos S. Fayt)

En la misma línea, en la sentencia "Estado Nacional (Ministerio de Cultura y Educación) c/Universidad Nacional de Lujan s/Aplicación Ley 24521"23 (1999), la CSJN expresó que "Las raíces históricas de la autonomía de las universidades argentinas, que hoy garantiza la Constitución Nacional, convierten en inviable toda limitación efectuada por el Congreso de la Nación, pues las universidades tienen por destino ser la conciencia intelectual de la sociedad" (Disidencia parcial del Dr. Carlos S. Fayt).

21 Finocchiaro, Alejandro, El mito reformista, Buenos Aires, Eudeba, 2018, p. 231.

22 Fallos: 321: 1799.

23 Fallos: 322: 842. 
Recientemente, el Consejo Superior de la Universidad de Buenos Aires emitió un comunicado en el cual puso de relieve el valor y la vigencia de los postulados reformistas en la acción del gobierno universitario:

El legado de la Reforma Universitaria de Córdoba de 1918 a través de sus postulados interpela a las instituciones de educación superior y las insta a revisar su presente y futuro para abordar los desafíos actuales que afronta nuestra región. En los espacios de discusión se analizaron los principios de la Reforma que cuales [sic] dotaron de un carácter singular a las Universidades Latinoamericanas, tales como la autonomía universitaria, la participación de profesores, estudiantes y graduados en el gobierno institucional, la función social de la universidad a través de la extensión, la libertad de cátedra y la docencia libre, la publicidad de los actos de la institución, los concursos para la selección de profesores y la periodicidad de la cátedra, la gratuidad de la enseñanza concebida como estrategia para lograr la justicia social y la necesidad de propiciar un pensamiento que cimiente la unidad latinoamericana. ${ }^{24}$

Todos estos principios ayudan a desentrañar el sentido o la finalidad de las distintas normas constitucionales, legales o estatutarias que se fueron dictando. En los autores citados se observa una profunda coincidencia sobre el impacto de la Reforma de 1918 en la vida universitaria argentina y sus repercusiones en Latinoamérica.

\section{2. El estatus de las universidades nacionales antes de la reforma constitucional de 1994}

Con anterioridad a la reforma constitucional de 1994, la doctrina se encontraba escindida en dos posiciones fundamentales

24 Documento "Aportes de la Universidad de Buenos Aires hacia la Conferencia Regional de Educación Superior de América Latina y el Caribe 2018", aprobado mediante Resolución (CS) 345/08, del 25 de abril del 2018. 
en torno al estatus de las universidades nacionales. La primera las consideraba sólo entes autárquicos. La segunda las concebía como entes autónomos.

En tal sentido, asumiendo la primera postura, desde el derecho administrativo Miguel Marienhoff explica lo siguiente:

... por entidad autárquica debe entenderse toda persona jurídica pública estatal que, con aptitud legal para administrarse a sí misma, cumple fines públicos específicos. De ahí que los rasgos esenciales de tales entidades son: 1) constituyen una persona jurídica; 2) trátase de una persona jurídica "pública"; 3) es una persona jurídica pública "estatal", vale decir, pertenece a los cuadros de la Administración Pública e integra los mismos; 4) realiza o cumple fines "públicos", que son fines propios del Estado; 5) su competencia o capacidad jurídica envuelve esencialmente la de 'administrarse' a sí misma, conforme a la norma que le dio origen; 6) siempre es creada por el Estado (...) Es necesario diferenciar la noción de "autarquía" de la de otras expresiones que, por aparejar ideas afines, podrían introducir confusiones (...) Mientras "soberanía" y "autonomía" implican conceptos políticos, "autarquía" y "autarcía" traducen conceptos administrativos. El concepto de "soberanía" puede ser analizado desde dos puntos de vista: a) En el orden externo, significa "autodeterminación", "independencia" en suma; b) en el orden interno traduce la potestas del Estado sobre las personas y bienes existentes en su territorio. La Nación Argentina es soberana. "Autonomía" significa que el ente tiene poder para darse su propia ley y regirse por ella. Nuestras provincias son autónomas, pero no soberanas. La autonomía, en suma, denota siempre un poder de legislación, que ha de ejercitarse dentro de lo permitido por el ente soberano. De modo que autonomía es un concepto "político", porque "político" es el poder de propia legislación. "Autarquía", en cambio, significa que el ente tiene atribuciones para administrarse a sí mismo, pero de acuerdo a una norma que le es impuesta (...) "Autarcía" traduce la idea de autosuficiencia económica. 
Entre nosotros hay algunos entes, como las universidades y las municipalidades, a cuyo respecto se ha discutido si son autónomos o autárquicos (...) En lo atinente a las "universidades", Bielsa y Villegas Basavilbaso las consideran "autárquicas"; Sánchez Viamonte las estima "autónomas". Comparto el criterio de quienes las tienen por meramente "autárquicas". ${ }^{25}$

A su turno, defendiendo la segunda posición, desde el derecho constitucional Humberto Quiroga Lavié afirma:

Cuestión preliminar será la de aclarar el concepto de autonomía, materia que los juristas, particularmente los dedicados a estudiar el derecho administrativo, han llevado y traído a la mano de razonamientos que resultan insuficientes, si la que se quiere son definiciones de sustancia y no de matices. El derecho político distingue la soberanía de la autonomía, ubicando a la primera como potestad propia del pueblo en ejercicio del poder constituyente, y a la segunda como potestad derivada de dicho poder, a ser ejercida por los entes públicos establecidos en la Constitución -las provincias, en el caso argentinopero respetando el marco normativo de la ley suprema (...) Se ha sostenido, enfáticamente, que la organización institucional argentina sólo prevé la autonomía de las provincias; por ende, mal podrían ser consideradas autónomas las universidades, las cuales sólo merecerían ser calificadas como autárquicas. El derecho administrativo ha hecho una cuestión de principio, con motivo de la referida distinción entre autonomía y autarquía. Lo cierto es que la autonomía es la potestad de todo sujeto titular de decisión de establecer sus propias reglas de acción. En tal sentido la autonomía es la sustancia misma del concepto de libertad, definida ésta como autodeterminación. De este modo, la autonomía es un género, y la soberanía, la autarquía y la libertad individual, manifestaciones de aquélla (...) Entonces, no tiene sentido ni es

Marienhoff, Miguel S., Tratado de Derecho Administrativo, t .1, Buenos Aires, AbeledoPerrot, 2011, pp. 307 y ss. 
correcto sostener que sólo son autónomas las provincias en el orden institucional argentino (...) Cada ente o persona jurídica ejerce su autonomía en el marco de la Constitución, de la ley y del ordenamiento jurídico al cual se refiere su desenvolvimiento (...) Si entendemos bien esto, ¿cómo negarle autonomía a las universidades? Lo propio, en cambio, es determinar cuál es el ámbito y el alcance de su ejercicio, quién se la otorga y quiénes pueden controlar su desenvolvimiento, si tal fuera el caso. Se trata de perfilar la ubicación de la universidad en el marco de la gestión pública. ${ }^{26}$

La reforma constitucional de 1994, como ya se adelantó, consagró expresamente la segunda solución al reconocer la "autonomía y autarquía" de las universidades nacionales.

\section{3. Las universidades nacionales en la Constitución Nacional}

La adopción de la forma de Estado federal implica la descentralización del poder en relación con el territorio. Del mismo modo, el principio republicano de gobierno divide el poder al repartir funciones. Los regímenes de las provincias, de la Ciudad Autónoma de Buenos Aires y de los municipios no son las únicas formas de descentralización que establece la Constitución Nacional (CN), las leyes e inclusive los reglamentos.

Balbín clasifica a los entes descentralizados de la siguiente manera: "a) entes autónomos; sean estos a.1. territoriales -provincias y municipios-; o a.2.institucionales -universidades-; b) entes autárquicos, es decir b.1. territoriales -regiones; o, b.2. institucionales -AFIP-; y c) entes no autárquicos -empresas y sociedades del Estado-"27. Véase que, de acuerdo con este autor, las universidades nacionales revisten la categoría de entes autónomos institucionales, lo cual conlleva personalidad jurídica propia.

\footnotetext{
26 Quiroga Lavié, Humberto, "La autonomía universitaria”, La Ley, t. 1987-B, pp. 724 y ss.

27 BalBín, ob. cit., p. 672.
} 
En relación con los entes que gozan de algún tipo de autonomía dada por la CN, se encuentran las provincias (art. 5); los municipios (arts. 5 y 123); las universidades nacionales (art. 75, inc. 19); la Auditoría General de la Nación (art. 85); el Defensor del Pueblo (art. 86); el Ministerio Público (art. 120) y la Ciudad Autónoma de Buenos Aires (art. 129). En cuanto al alcance de la autonomía de cada uno de estos entes, la CN no formula una enumeración taxativa de las competencias que ella implica, por lo que le corresponde al Congreso Nacional precisar razonablemente su significación, pero sin desvirtuar el espíritu de la manda constitucional.

En el caso de las universidades nacionales, antes de la reforma se sostenía que eran autárquicas o que gozaban de una autonomía acotada, sólo vinculada a los aspectos elementales de la enseñanza, la investigación y el autogobierno. En esta línea, la CSJN, en la causa "Universidad Nacional de Buenos Aires c/Estado Nacional (PEN) s/inconstitucionalidad de decreto" (1991), sostuvo que las provincias "son las únicas entidades autónomas porque se dictan sus propias normas"28. En 1993 la Ley Federal de Educación $24.195^{29}$ estableció que "Las universidades gozan de autonomía académica y autarquía administrativa y económico-financiera en el marco de una legislación específica" (art. 23). De este modo, sólo se circunscribió la autonomía a las cuestiones académicas.

La reforma constitucional zanjó esta discusión al explicitar la autonomía y autarquía en el texto de la CN. El Congreso Nacional reglamentó la autonomía en 1995, al dictar la Ley de Educación Superior $24.521^{30}$, cuyo artículo 29 estableció lo siguiente:

Las instituciones universitarias tendrán autonomía académica e institucional, que comprende básicamente las siguientes atribuciones:

\footnotetext{
28 Fallos: 314: 570.

29 Sancionada el 14/4/1993 y promulgada el 29/4/1993.

30 Sancionada el 20/7/1995 y promulgada el 7/8/1995.
} 
a) Dictar y reformar sus estatutos, los que serán comunicados al Ministerio de Cultura y Educación a los fines establecidos en el artículo 34 de la presente ley;

b) Definir sus órganos de gobierno, establecer sus funciones, decidir su integración y elegir sus autoridades de acuerdo a lo que establezcan los estatutos y lo que prescriba la presente ley;

c) Administrar sus bienes y recursos, conforme a sus estatutos y las leyes que regulan la materia;

d) Crear carreras universitarias de grado y de posgrado;

e) Formular y desarrollar planes de estudio, de investigación científica y de extensión y servicios a la comunidad incluyendo la enseñanza de la ética profesional y la formación y capacitación sobre la problemática de la discapacidad;

f) Otorgar grados académicos y títulos habilitantes conforme a las condiciones que se establecen en la presente ley;

g) Impartir enseñanza, con fines de experimentación, de innovación pedagógica o de práctica profesional docente, en los niveles preuniversitarios, debiendo continuar en funcionamiento los establecimientos existentes actualmente que reúnan dichas características;

h) Establecer el régimen de acceso, permanencia y promoción del personal docente y no docente;

i) Designar y remover al personal;

j) Establecer el régimen de admisión, permanencia y promoción de los estudiantes, así como el régimen de equivalencias;

k) Revalidar, solo como atribución de las universidades nacionales, títulos extranjeros;

1) Fijar el régimen de convivencia;

m) Desarrollar y participar en emprendimientos que favorezcan el avance y aplicación de los conocimientos;

n) Mantener relaciones de carácter educativo, científicocultural con instituciones del país y del extranjero; 
ñ) Reconocer oficialmente asociaciones de estudiantes, cumplidos que sean los requisitos que establezca la reglamentación, lo que conferirá a tales entidades personería jurídica. (énfasis agregado)

Nótese que la redacción de la ley, antes de enumerar las atribuciones que comprende la autonomía universitaria, utiliza el término "básicamente". Ello sugiere que las potestades autonómicas no se agotan en la Ley de Educación Superior; sino que, por el contrario, se está regulando el piso mínimo de competencias de las universidades, permitiendo un margen de apreciación para que éstas puedan autodeterminarse o desarrollar las tareas que le son propias.

En el caso "Monges, Analía M. c/UBA (Universidad de Buenos Aires) Resolución 2314/95"31 (1996), la CSJN parecería tener una interpretación similar sobre el alcance de la regulación, toda vez que se expresó en los siguientes términos: "Que el art. 29 de la ley 24.521 define, en general, la autonomía académica e institucional de las universidades" (énfasis agregado). La utilización del término "general" da cuenta de que la autonomía no se agota en la ley. Frente a este panorama, no resulta sencillo construir una definición acabada del término "autonomía" que nos permita identificar con claridad las competencias del Congreso Nacional y de las universidades nacionales en torno a la educación superior.

De acuerdo con Alterini, la autonomía significa “... la posibilidad de autodeterminación de las universidades públicas, y comprende lo normativo, lo institucional, lo político, lo administrativo y lo académico"32. En la misma línea, María Angélica Gelli entiende lo siguiente:

La autonomía implica la competencia de las universidades nacionales para darse sus estatutos de estructura, organización y funcionamiento y, a la vez, la capacidad

31 Fallos: 319: 3148.

32 AlterinI, ob. cit., p. 113. 
para autogobernarse de acuerdo a los criterios propios, eligiendo a sus autoridades y profesores, fijando el régimen disciplinario sin interferencia alguna de los Poderes Legislativo y Ejecutivo. ${ }^{33}$

En pos de garantizar la autonomía universitaria de la injerencia del Poder Ejecutivo, la LES establece que sólo podrán ser intervenidas por decisión del Congreso Nacional y sin afectación de la faz académica ${ }^{34}$. Asimismo, se regula un recurso de apelación ante la Cámara Federal contra las resoluciones definitivas de las universidades, de modo que se impide la intervención del órgano ejecutivo en la impugnación ${ }^{35}$. En el citado caso "Monges", la CSJN explicó que "El objetivo de la autonomía es desvincular a la universidad de su dependencia del Poder Ejecutivo, mas no de la potestad regulatoria del Legislativo, en la medida en que ella se enmarque en las pautas que fijó el constituyente" ${ }^{36}$ (Voto del Dr. Adolfo Roberto Vázquez).

En "Estado Nacional (Ministerio de Cultura y Educación) c/Universidad Nacional de Luján s/Aplicación Ley 24.521"37 (1999), se otorgó un sentido amplio al concepto:

La expresión "autonomía universitaria" debe ser interpretada más allá de su sentido técnico -potestad de todo sujeto titular de decisión de establecer sus propias

33 Gelul, María Angélica, Constitución de la Nación Argentina: comentada y concordada, Buenos Aires, La Ley, 2005, p. 698.

34 “Art. 30: Las instituciones universitarias nacionales sólo pueden ser intervenidas por el Honorable Congreso de la Nación, o durante su receso y ad referéndum del mismo, por el Poder Ejecutivo nacional por plazo determinado -no superior a los seis meses-y sólo por alguna de las siguientes causales: a) Conflicto insoluble del o de la institución que haga imposible su normal funcionamiento; b) Grave alteración del orden público; c) Manifiesto incumplimiento de la presente ley. La intervención nunca podrá menoscabar la autonomía académica".

35 "Art. 32: Contra las resoluciones definitivas de las instituciones universitarias nacionales impugnadas con fundamento en la interpretación de las leyes de la Nación, los estatutos y demás normas internas, sólo podrá interponerse recurso de apelación ante la Cámara Federal de Apelaciones con competencia en el lugar donde tiene su sede principal la institución universitaria".

36 Fallos: 319: 3148, 326: 1355, 322: 919 y 321: 1799.

37 Fallos: 322: 842. 
reglas de acción en un ámbito de libertad definido como autodeterminación-, trascendiendo el marco meramente jurídico para manifestar una aspiración o ideal de independencia, plasmado además en la creencia ampliamente compartida de que es bueno y deseable que, en el cumplimiento de las delicadas tareas a su cargo y en el manejo de sus propios asuntos, las universidades gocen de la mayor libertad de acción compatible con el régimen constitucional al que deben pleno acatamiento. (Voto del Dr. Adolfo Roberto Vázquez)

Respecto al abanico de estipulaciones que contiene la LES, entiendo que se puede esbozar una explicación que las vincule con los distintos tipos de competencias que poseen las universidades y el Congreso. En primer lugar, la LES regula atribuciones exclusivas del Poder Legislativo. Esto sucede, por ejemplo, cuando establece las causales de intervención de las universidades. Con este tipo de cláusulas el Congreso regla su propia actuación a fin de garantizar la autonomía de las universidades. En segundo lugar, la LES explicita atribuciones exclusivas de las universidades. El término "explicitar" lo utilizo con un alcance distinto al concepto de "regular". Al explicitar, la ley reconoce facultades propias de las universidades que derivan directamente de la CN. Ello implica que podrían no estar enunciadas en la LES y de todos modos las universidades podrían ejercerlas, en virtud de que tienen que ver con el núcleo esencial del quehacer universitario. Por lo tanto, no pueden ser alcanzadas o desvirtuadas por la regulación del Congreso. A modo de ejemplo, repárese que la intervención de una universidad por parte del Congreso nunca puede alcanzar la faz académica. Por último, la LES también regula las atribuciones concurrentes del Congreso y las universidades.

Conforme a lo expuesto en los apartados anteriores, la $\mathrm{CN}$ confiere autonomía a las universidades nacionales, pero no determina puntualmente cuál es el ámbito de la competencia material que corresponde a los estatutos universitarios, ni cuál es el rango de su jerarquía formal. A continuación procuro aportar elementos para responder estos interrogantes. 


\section{4. Ámbito de la competencia material de los estatutos universitarios}

A diferencia de otros entes descentralizados que son creados por ley y deben su existencia y competencias a la voluntad del Congreso Nacional, el estatus autonómico de las universidades nacionales proviene directamente de la $\mathrm{CN}$. Sin embargo, esa autonomía de rango constitucional no independiza a las universidades nacionales de la voluntad del Congreso Nacional para definir las políticas públicas generales del sistema educativo.

Bien se ha sostenido que "en nuestro sistema jurídico, la ley es la más importante fuente interna del derecho objetivo, debajo de la Constitución" 38 . No obstante, su alcance se extiende a la "reglamentación" de los derechos fundamentales, aunque sin poder ir más allá, pues las disposiciones de la $\mathrm{CN}$ "poseen un contenido esencial que el poder constituyente estableció indisponible para el Congreso"39. Ello, claramente, es una consecuencia de lo previsto en el artículo 28, según el cual "Los principios, garantías y derechos reconocidos (...) no podrán ser alterados por las leyes que reglamenten su ejercicio".

En este trabajo se trata de reflexionar acerca del alcance de la "autonomía" reconocida a las universidades nacionales en el artículo 75 , inciso 19 , párrafo $3, \mathrm{CN}$, con el objeto de dilucidar los ámbitos que corresponden a la regulación de los estatutos universitarios y los campos referidos a la reglamentación de las leyes estatales. Desentrañando el tema, Gelli explica lo siguiente:

... puede afirmarse que la autonomía universitaria no convierte a estas instituciones en un poder soberano dentro del Estado. La finalidad de aquélla consiste en independizar y desvincular a las universidades de la injerencia del Poder Ejecutivo, pero quedan sujetas a

38 Ferreyra, Raúl Gustavo, Notas sobre Derecho Constitucional y garantías, Buenos Aires, Ediar, 2016, pp. 218 y ss.

39 Ibíd. 
la reglamentación del Poder Legislativo, dentro de los límites que la Constitución Nacional le impone al Congreso, y sometidas al eventual control jurisdiccional. ${ }^{40}$

Sobre los límites de la autonomía de las universidades ante las decisiones del Congreso Nacional, la CSJN, en "Biasizo, Rogelio José c/UTN s/Empleo Público"11 (2017), sostuvo que "Por amplia que sea la autonomía consagrada por la reforma constitucional, ésta no deja de estar engarzada en el ordenamiento jurídico en general, sin que pueda sostenerse que la autonomía universitaria es por sí misma un poder en sentido institucional".

En el mismo sentido, en "Universidad Nacional de Mar del Plata c/Banco Nación Argentina s/daños y perjuicios"² (2003), la CSJN expresó:

Se tiende a una universidad como un organismo independiente, con personalidad jurídica propia y que pueda expresarse en una capacidad de auto-organización y de auto-decisión; sin embargo, la autonomía de la universidad no implica su aislamiento respecto del entramado institucional, está inmersa en el universo de las instituciones públicas, es afectada por aquéllas y debe responder a los controles institucionales propios del estado de derecho.

Con esta afirmación, queda de manifiesto que la autonomía constitucional es relativa, por cuanto es indudable que está condicionada por la legislación que dicta el Congreso Nacional en las materias que son de su competencia exclusiva y en las concurrentes.

En cuanto al control judicial de constitucionalidad, en "Piaggi, Ana Isabel c/Universidad de Buenos Aires (UBA) Resolución 3582/2000" ‘3 (2004), la CSJN planteó que "La autonomía uni-

\footnotetext{
40 Gell, ob. cit., p. 698.

41 Fallos: 340: 983.

42 Fallos: 326: 1355.

43 Fallos: 327: 2678.
} 
versitaria no puede ser entendida de tal manera que implique colocar a las universidades, en el plano normativo, al margen de todo control de constitucionalidad y legalidad...”. Así como anteriormente se expresó que la autonomía no es absoluta con relación al Congreso Nacional, tampoco sus actos están exentos del control del Poder Judicial.

La potestad reglamentaria del Congreso Nacional está configurada en el artículo 75, incisos 18 y 19, CN. El primer inciso, conocido como "cláusula del progreso", lo faculta a "Proveer lo conducente a la prosperidad del país, al adelanto y bienestar de todas las provincias, y al progreso de la ilustración, dictando planes de instrucción general y universitaria”. El segundo inciso, o "cláusula del nuevo progreso", le permite "Sancionar leyes de organización y de base de educación (...) y que garanticen los principios de gratuidad y equidad de la educación pública estatal y la autonomía y autarquía de las universidades nacionales".

En ambos casos, la educación superior es concebida como el medio de satisfacción de un conjunto de fines estatales. Estas cláusulas no operan de manera independiente, por lo que necesariamente deben vincularse para desentrañar el contenido de la atribución regulatoria del legislador. De igual modo, el principio de autonomía carece de entidad propia, por lo que se complementa con la voluntad legislativa, al momento de definir los rasgos principales del modelo educativo de acuerdo a los fines que persigue la Constitución.

Por una parte, en cuanto al rol que le cabe al Congreso Nacional en materia educativa, en "Universidad Nacional de Córdoba (doctor Eduardo Humberto Staricco -rector) c/Estado Nacional -declaración de inconstitucionalidad- sumario" ${ }^{4}$ (1999), la CSJN argumentó:

Que la responsabilidad indelegable del Estado a la que hace referencia el art. 75, inc. 19, deja en claro que aquél no puede desatender la educación pues el constituyente

44 Fallos: 322: 919. 
le confió con carácter propio una materia que constituye, a no dudarlo, uno de los objetivos primordiales de la Nación. La educación es la base del desarrollo personal del ser humano, por ello el Estado tiene el deber indelegable de garantizar el derecho a la educación y estructurar un sistema educativo permanente. Por mandato constitucional el Congreso está obligado a definir el modelo institucional de la universidad estatal, de manera que asegure la vigencia de determinados principios y garantías que también se hallan insertos en la Constitución Nacional y en los tratados que ostentan jerarquía constitucional, tales como la igualdad de oportunidades y posibilidades, la no discriminación, el derecho de enseñar y aprender...

En torno a las relaciones entre las competencias del Congreso Nacional y las universidades, la CSJN, en "Ministerio de Cultura y Educación - Estado Nacional s/art. 34 de la ley 24.521" 45 (2008), expresó que "El mandato del art. 75, inc. 19, vincula al legislador, respeto de los alcances de la reglamentación en la materia, así como a las universidades, en tanto y en cuanto el principio de autonomía no debe independizarse del resto de las condiciones impuestas en la norma y por las cuales el Estado debe velar".

Por otra parte, respecto del papel del Poder Ejecutivo en estos temas, la $\mathrm{CN}$ no le confiere ningún tipo de atribución materialmente legislativa. Sin embargo, puede reglamentar las leyes, incluso las vinculadas a las universidades, pero cuidando de no alterarlas al establecer los pormenores para su ejecución. En este sentido, el Ejecutivo puede actuar dentro del terreno que establezca el Congreso al dictar las leyes de educación superior, pero sólo en lo que relativo a su aplicación por parte de la Administración Nacional.

Asimismo, el Poder Ejecutivo tiene vedado, de acuerdo al entramado constitucional, el dictado de decretos de necesidad y urgencia conforme a una correcta interpretación del artículo 99,

45 Fallos: 331: 1123. 
inciso 3, $\mathrm{CN}^{46}$. El Congreso Nacional tampoco puede delegar al Presidente este tipo de legislación en los términos del artículo 76 , CN. A pesar de la prohibición constitucional, el Ejecutivo ha creado universidades nacionales mediante la utilización de decretos de necesidad y urgencia. ${ }^{47}$

En cuanto a la competencia material de las universidades, comparto la postura de Balbín, quien sostiene que éstas poseen un ámbito regulatorio que no puede ser alcanzado por la Administración dado que se encuentra relacionado con los quehaceres específicos que le encomienda la $\mathrm{CN}$.

... son autónomas porque ejercen poder regulatorio reglamentario, tal es el caso de los estatutos universitarios; y sin sujeción respecto de las potestades normativas del Poder Ejecutivo. Es decir, las universidades tienen un campo normativo de nivel reglamentario exclusivo y excluyente del Ejecutivo. Precisemos que este poder exclusivo sólo comprende los aspectos vinculados con su especialidad, esto es, las libertades académicas y de cátedra; de modo que el Poder Ejecutivo sí puede reglamentar los otros aspectos del ente universitario que no guarden relación con ello, por ejemplo, los asuntos de postgrado; el régimen de educación a distancia; o el procedimiento de designación de los miembros de la Comisión Nacional de Evaluación y Acreditación de las universidades. En otros términos, el poder de reglamentar los detalles o pormenores de las leyes universitarias es propio de las universidades. ${ }^{48}$

\footnotetext{
46 En contra de este mecanismo, la Ley de Educación Superior dispone lo siguiente: "Las instituciones universitarias nacionales son personas jurídicas de derecho público, que sólo pueden crearse por ley de la Nación, con previsión del crédito presupuestario correspondiente y en base a un estudio de factibilidad que avale la iniciativa. El cese de tales instituciones se hará también por ley. Tanto la creación como el cierre requerirán informe previo del Consejo Interuniversitario Nacional" (art. 48).

47 Por ejemplo, los DNU 2615/2002 y 2617/2002 de creación de la Universidad Nacional de Chilecito y la Universidad Nacional del Noroeste de la Provincia de Buenos Aires, respectivamente.

48 Balbín, ob. cit., p. 671.
} 
Aquí es importante tomar la noción del criterio de la especialidad para aproximarse más certeramente al abanico de competencias que comprende la autonomía universitaria. El autor citado afirma que "... el reconocimiento del poder reglamentario de las universidades en su condición de entes autárquicos y autónomos está basado en el principio constitucional de la especialidad que nace particularmente del artículo 75 , CN..." ${ }^{49}$. Entiendo que el parámetro de la especialidad permite analizar el campo de competencias materiales de las universidades bajo la óptica de los fines que persiguen y los medios que se articulan para satisfacerlos.

En este orden de ideas, en cuanto a los fines o propósitos de la autonomía de las universidades, la CSJN, en el caso "Ministerio de Cultura y Educación - Estado Nacional s/art. 34 de la Ley $24.521^{150}$ (2008), sostuvo lo siguiente:

La armonización de las previsiones contenidas en los considerandos 18 y 19 del art. 75 de la Constitución Nacional exige reconocer como límite de la competencia del Congreso para legislar en materia de planes de instrucción universitaria la no afectación de la teleología de la autonomía universitaria. (Voto del Dr. Carlos S. Fayt)

El criterio de la especialidad y la filosofía de la teleología se emparentan, puesto que apuntan a los fines que persiguen las cosas.

La CSJN, en la causa "Universidad Nacional de Rosario c/Entre Ríos, Provincia de s/Amparo - Daño Ambiental" (2014), definió el ámbito competencial de las universidades haciendo uso del criterio de la especialidad:

Cabe hacer lugar a la excepción de falta de legitimación activa opuesta por la provincia demandada, respecto de la Universidad actora que promovió una acción de amparo a fin de que cese la supuesta quema de pastizales, pues

\footnotetext{
49 Balbín, ob. cit., p. 672.

50 Fallos: 331: 1123.
} 
ello excede las facultades propias de dicha entidad autónoma, dado que las personas públicas tienen un campo de actuación limitado por su especialidad... ${ }^{51}$

Por lo expuesto hasta aquí, considero que la posibilidad de autodeterminación en distintos campos debe estar necesariamente vinculada al criterio de la especialidad. Esto implica dos cuestiones: primero, que el Congreso Nacional debe regular la autonomía universitaria conforme a este parámetro, es decir, atendiendo a la razón de ser de estas entidades; segundo, que las universidades deben ejercer esta libertad teniendo presente la función que le encomienda la $\mathrm{CN}$ y el Congreso Nacional.

\section{5. Rango de la jerarquía formal de los estatutos universitarios}

El estatuto es la norma madre que organiza la vida de las universidades y de las distintas Facultades que las componen en sus aspectos institucionales, políticos, administrativos y académicos. Esta potestad se deriva de la autonomía otorgada por la $\mathrm{CN}$ y es explicitada por el Congreso Nacional mediante la ley de Educación Superior.

El estatuto universitario se posiciona como la norma de mayor relevancia para cada universidad y, lógicamente, debe guardar conformidad con la $\mathrm{CN}$ y los tratados de derechos humanos con jerarquía constitucional, toda vez que se encuentran ubicados en el máximo nivel normativo. Sostengo que el estatuto sólo debe reportarse en términos de jerarquía a las leyes que establezcan el marco general de políticas públicas de la educación superior. Estas últimas normas determinan, entre otras cuestiones, el modelo educativo y precisan los contornos de la autonomía universitaria.

En este sentido, Alterini explica que la autonomía normativa “... implica la potestad de dictar sus propias normas regulatorias con la sola exigencia de respetar las instituciones de la

51 Fallos: 337: 1447. 
República y la Constitución Nacional" ${ }^{52}$. De este modo, el orden jerárquico vinculado a las universidades nacionales se estructura de manera diferente en virtud del principio de competencia material. Los estatutos no se subordinan a la totalidad de las leyes dictas por el Congreso Nacional, sino tan sólo a aquellas dictadas en ejercicio de la potestad consagrada en el artículo 75, incisos 18 y 19, CN.

En otros términos, cuando el Congreso legisla materias de competencia concurrente, los estatutos universitarios deben prestar conformidad con esa normativa. Por el contrario, cuando se está en presencia de competencias exclusivas de las universidades públicas, los estatutos no se encuentran condicionados por ningún tipo de legislación. Finalmente, si el Congreso ejerce atribuciones exclusivas en materia educativa, los estatutos no entran en juego.

El reparto de competencias reseñado da lugar a distintos escenarios. En un primer escenario, el de las competencias concurrentes, el Congreso define de manera general el modelo educativo universitario y los estatutos deben guardar conformidad con éste. En un segundo escenario, el de las competencias exclusivas de las universidades, al tratarse de aspectos sustanciales de la vida universitaria, como por ejemplo la libertad de cátedra, los estatutos se encuentran sólo por debajo de la $\mathrm{CN}$ y los tratados con jerarquía constitucional. Sugiero esto último en el entendimiento de que las universidades poseen un campo regulatorio que no puede ser alcanzado por las leyes del Congreso como consecuencia de su autonomía derivada de la CN. En un tercer escenario, el de las competencias exclusivas del Congreso, las leyes prevalecen sobre los estatutos, aunque no pueden vulnerar el espíritu de la autonomía constitucional de las universidades.

A grandes rasgos, en el escenario de las competencias concurrentes, la ordenación normativa quedaría de la siguiente forma:

52 AlterinI, ob. cit., p. 113. 
1. La CN / Los tratados de derechos humanos con jerarquía constitucional.

2. Las leyes dictadas de conformidad con el artículo 75, incisos 18 y 19, CN.

3. Los estatutos universitarios.

En el escenario de las competencias exclusivas de las universidades, la ordenación normativa quedaría de la siguiente forma:

1. La CN / Los tratados de derechos humanos con jerarquía constitucional.

2. Los estatutos universitarios.

En el escenario de las competencias exclusivas del Congreso, la ordenación normativa quedaría de la siguiente forma:

1. La CN / Los tratados de derechos humanos con jerarquía constitucional.

2. Las leyes.

Por el momento, excluyo del análisis las potestades del Poder Ejecutivo en materia de educación superior. De todos modos, adelanto mi posición en pocas palabras. Si bien el Ejecutivo tiene la atribución constitucional de reglamentar las leyes, no puede entrometerse en el funcionamiento de las universidades. Sólo puede utilizar esa facultad para reglar los temas que se vinculan con el ejercicio de la propia actividad de la Administración.

A fin de advertir cómo el criterio de competencia abre distintos caminos $u$ órdenes en materia educativa, es interesante enunciar la situación de las provincias en cuanto a la educación escolar. Por un lado, las provincias deben asegurar la educación primaria (art. 5, CN); y, por el otro, el Congreso Nacional dicta los planes de instrucción general y sanciona las leyes de organización y de base de la educación (art. 75, incs. 18 y 19, $\mathrm{CN})$. Frente a estas disposiciones, se configura un reparto de competencias concurrentes entre la Nación y las provincias. Entonces, en lo que concierne a la educación primaria, el orden 
jerárquico se presenta diferente al universitario, toda vez que los estatutos no aparecen en escena, ya que pertenecen a otro campo regulatorio.

\section{La articulación entre las leyes estatales y los estatutos universitarios}

En materia de educación superior, la $\mathrm{CN}$ le asigna tareas tanto al Congreso como a las universidades públicas. Dado que el texto constitucional no formula una enumeración taxativa de las funciones de cada institución, los límites del campo de actuación de cada una no son precisos y pueden generarse situaciones complejas. Puede haber casos en que la ley invada la autonomía universitaria y otros en que los estatutos se entrometan en temas que son competencia del Congreso.

Estos conflictos normativos no se resuelven por medio de la aplicación del principio jerárquico, es decir, haciendo prevalecer de manera automática la ley sobre el estatuto universitario. Ello responde a que la regulación de algunos temas le corresponde al Congreso y otros, a las universidades. Por lo tanto, en ciertas cuestiones la ley vale más que los estatutos, mientras que en otras se observa lo contrario. En definitiva, el principio de competencia es el que determina si las normas en juego son constitucionales. A continuación, analizo distintas situaciones que pueden darse entre las leyes y los estatutos.

\section{1. Ley estatal incompatible con la autonomía universitaria}

El vigente Estatuto de la Universidad de Buenos Aires data de 1958. Cabe aclarar que fue suspendido en 1966, cuando fue derrocado Arturo Illia, y se restableció en 1983, con pequeñas modificaciones, a partir de la recuperación de la democracia con el gobierno de Raúl Alfonsín. En cuanto al espíritu del Estatuto, Lucas Luchilo sostiene que éste “... supuso una codificación de las ideas, principios y dispositivos institucionales de la universidad reformista, con un grado de precisión que probablemente 
no haya tenido antecedentes en la historia institucional de la universidad argentina" ${ }^{3}$.

En tal Estatuto se establecen las diferentes categorías del personal docente a cargo de la enseñanza. El primer distingo es entre profesores y auxiliares docentes. Los profesores son "1. Profesores regulares. a) Titulares plenarios, titulares y asociados; b) Adjuntos. 2. Profesores consultos. 3. Profesores contratados e invitados. 4. Profesores eméritos y honorarios" (art. 34). Los auxiliares docentes son "a) jefe de trabajos prácticos; b) ayudantes primeros; y, c) ayudantes segundos” (art. 65). Los profesores regulares son designados por concurso y por el término de siete años. El año del vencimiento del plazo se debe llamar nuevamente a concurso (arts. 37, 42, 44, 45 y 46).

En relación con el régimen de permanencia, el artículo 51 establece lo siguiente:

Todo profesor regular cesa en las funciones para las que ha sido designado el $1^{\circ}$ de marzo del año siguiente a aquel en el que cumple sesenta y cinco años de edad. En tal circunstancia el profesor regular puede ser designado profesor consulto (en la categoría respectiva) o profesor emérito. En caso de que el profesor regular no sea designado profesor consulto ni profesor emérito y no esté en condiciones de acogerse a los beneficios de la jubilación, es indemnizado de la manera que reglamente el Consejo Superior. La designación de profesor consulto la propone el Consejo Directivo de la Facultad al Consejo Superior de la Universidad. Para merecer esta distinción se requiere el voto favorable de nueve miembros del Consejo Directivo, el cual tendrá en cuenta las actividades científicas y docentes del profesor regular.

\footnotetext{
53 LuCHILO, Lucas, "El gobierno de la universidad reformista: los debates para el Estatuto de la Universidad de Buenos Aires (1958)", en Albornoz, Mario y Crespo, Manuel (comp.), La universidad reformada: hacia el centenario de la reforma universitaria de 1918, Ciudad Autónoma de Buenos Aires, Eudeba, 2017, p. 229.
} 
Esta disposición del Estatuto está avalada por la Ley de Educación Superior, en la parte que dispone que las universidades pueden "Establecer el régimen de acceso, permanencia y promoción del personal docente y no docente" (art. 29, inc. h).

Hasta aquí, según las normas estatutarias, los profesores regulares, sin distinción de género, cesan en sus funciones a los 65 años de edad y, para continuar, deben ser designados profesores consultos ${ }^{54}$ o eméritos ${ }^{55}$ por el Consejo Directivo de la Facultad y el Consejo Superior de la Universidad. De lo contrario, si están en edad de jubilarse, son indemnizados de acuerdo a la reglamentación.

Ahora bien, en el 2009 el Congreso Nacional dictó la Ley $26.508^{56}$, denominada del "Personal docente de las universidades públicas nacionales. Jubilaciones y Pensiones. Beneficios", la cual en su artículo 1 dispuso lo siguiente:

a) Tendrán derecho a la jubilación ordinaria docente universitaria los docentes universitarios que reúnan los siguientes requisitos: 1) Tener veinticinco (25) años de servicio universitarios docentes de los cuales diez (10) como mínimo continuos o discontinuos deben ser al frente de alumnos. Cuando no puedan acreditarse períodos completos del lapso exigido de servicios universitarios, los mismos serán considerados servicios comunes a los efectos del haber de la prestación, rigiéndose por el régimen previsional general vigente. 2) Haber cumplido los sesenta (60) años de edad en el caso de las mujeres y sesenta y cinco (65) años de

\footnotetext{
54 “Art. 52: El Profesor consulto colabora en el dictado de cursos especiales para alumnos y graduados y continúa en sus tareas de investigación, todo con acuerdo del Consejo Directivo. Son aplicables a los profesores consultos las disposiciones del art. 44 en lo relativo a la renovación y caducidad de su designación".

55 "Art. 56: Profesor emérito es el profesor titular plenario o profesor titular que ha llegado a la edad de sesenta y cinco años y a quien, en virtud de haber revelado condiciones extraordinarias tanto en la docencia como en la investigación, lo propone para esa categoría el Consejo Directivo de la respectiva Facultad por el voto unánime de sus componentes".

56 Sancionada el 20/8/2009 y promulgada el 3/9/2009.
} 
edad los varones. En ambos casos, ante la intimación del empleador, cualquiera fuere, los docentes universitarios podrán optar por permanecer en la actividad laboral durante cinco (5) años más después de los sesenta y cinco (65) años.

El dictado de esta ley produjo conflictos con el estatuto, ya que generó un estado de situación en el cual los docentes universitarios de 65 años, que no hayan sido designados consultos o eméritos, podrían permanecer en la actividad laboral durante cinco años más. A raíz de ello, el 16 de marzo de 2011 el Consejo Superior de la Universidad de Buenos Aires, mediante Resolución (CS) No 2067/1157, dictó un instructivo sobre la aplicación de la Ley 26.508 en el ámbito de la universidad.

57 “1. La posibilidad de opción prevista por el art. $1^{\circ}$, inciso a) apartado 2 último párrafo de la Ley $n^{0} 26508$, solo podrá ser ejercida por aquellos profesores o auxiliares docentes que hayan cumplido 65 años de edad con posterioridad al $1^{\circ}$ de octubre de 2009 y que ostentaran un cargo docente regular vigente al momento de la opción o se encontraren inscriptos y/o en trámite de sustanciación de concursos de renovación. 2. Dicha opción consistirá exclusivamente en la posibilidad de concluir el período para el que fueron designados por concurso, no obstante el cumplimiento de los 65 años de edad, debiendo cesar automáticamente al término de dicha designación o al cumplimiento de los 70 años de edad, lo que suceda primero. 3. En el caso que el profesor o auxiliar docente cumpla 65 años de edad, durante la tramitación del concurso y al cual se hubiera inscripto con anterioridad y que hubiere ejercido la opción prevista en el punto 1), si resultare nombrado en el cargo, la designación no deberá ni extenderse más allá de lo originalmente previsto, ni tampoco tener una extensión superior a los 70 años de edad del docente. 4. Se ratifica la plena vigencia del art. $8^{\circ}$ inciso a) del Reglamento aprobado por Resolución (CS) n 1670/10. 5. No se admitirán las inscripciones a los concursos de Profesores o Auxiliares Docentes, que posean más de 65 años a la fecha de la inscripción. 6. Asimismo se ratifica la plena vigencia del régimen aprobado por Resoluciones (CS) Nros. 3170/89 y 2344/03 y sus modificatorias. 7. El ejercicio de la opción por quién ostente también un cargo no docente en esta Universidad, no será óbice respecto de que se lo intime a iniciar sus trámites jubilatorios a los 65 años de edad y se le dé la baja como trabajador no docente luego del plazo de ley, siendo tal circunstancia totalmente independiente de su continuidad como profesor o auxiliar docente. 8. Se deja expresamente establecido, que la falta de otros requisitos por parte del profesor y/o auxiliar docente para acceder a la jubilación especial de la Ley $n^{0} 26508$, no podrá bajo ninguna circunstancia ampliar el tope de 70 años previsto ni los términos del concurso y/o designación. En tales supuestos, el profesor y/o auxiliar docente, deberá tramitar su jubilación conforme al régimen general. 9. Los docentes que se encuentre en condiciones de ejercer la opción indicada en los incisos 1, 2 y 3, deberán cumplir con los siguientes requisitos: a. Ejercer la 
Planteada la cuestión, y dado el marco normativo involucrado, corresponde en adelante analizar si la Ley 26.508 resulta violatoria de la autonomía académica universitaria, al permitir prolongar voluntariamente el ejercicio de la actividad docente, en colisión con lo dispuesto por el Estatuto de la Universidad de Buenos Aires.

Para comenzar, es conveniente distinguir entre régimen de permanencia y régimen de jubilación. De acuerdo al principio de autonomía y su reglamentación en la Ley de Educación Superior, las universidades nacionales pueden establecer las condiciones de permanencia de sus docentes. En ese entendimiento, el artículo 51 del Estatuto de la Universidad de Buenos Aires dispone como límite para el ejercicio de la docencia la edad de 65. Esta regla admite excepciones ya que los órganos del gobierno universitarios pueden realizar las designaciones especiales de profesores consultos o eméritos. Según Alterini, esta faceta de la autonomía "... garantiza la plena libertad desde los puntos de vista científico, ideológico y político para la organización de la docencia y de la investigación científica" ${ }^{58}$.

La regulación del régimen de permanencia se vincula necesariamente con ciertos principios de la reforma universitaria, como el de la periodicidad de las cátedras y el de acceso o permanencia por medio de concursos de antecedentes y oposición. Estos valores se insertan dentro de la autonomía académica ${ }^{59}$

opción por nota ante la Oficina de Personal de la Unidad Académica que se trate, desde el $1^{\circ}$ de diciembre hasta el 31 de diciembre del año en que han alcanzado los 65 años. b. Adjuntar copia del Documento Nacional de Identidad. c. Denunciar y/o actualizar el domicilio real del docente al momento de ejercer la opción. 10. Toda opción ejercida que no se ajuste al presente instructivo, deberá ser expresamente rechazada y se procederá a la continuidad de la tramitación de la baja en los términos del artículo 51 del Estatuto Universitario. 11. En forma transitoria, los docentes que han cumplido 65 años desde la entrada en vigencia de la Ley 26508 hasta la fecha, tendrán plazo de 30 días desde la publicación de la presente, para ejercer la opción, si no hubieran sido intimados oportunamente".

58 Alterini, ob. cit., pp. 114-115.

59 En el caso "Universidad Nacional de Córdoba (doctor Eduardo Humberto Staricco - rector) c/Estado Nacional - declaración de inconstitucionalidad - sumario" (1999), CSJN, Fallos: 322: 919, se sostuvo sobre la autonomía académica: “Es el ámbito académico en el que debe 
de las universidades y tienen como finalidad evitar que los cargos docentes se transformen en títulos de carácter vitalicio, que atenten contra la producción permanente de pensamiento crítico $^{60}$.

La Ley 26.508 define los requisitos para acceder a la jubilación ordinaria docente universitaria y, dentro de ellos, establece el derecho de opción de los docentes para continuar en actividad hasta los 70 años de edad. Sin lugar a dudas, es una atribución exclusiva del Congreso Nacional dictar las normas relativas a la seguridad social, conforme los artículos 14 bis $^{61}$ y 75, inciso 12, CN, incluida la del personal docente de las universidades nacionales. Efectivamente, la ley de referencia configura un régimen jubilatorio al requerir 25 años de servicio, que diez sean al frente de alumnos como mínimo, tener 60 o 65 años de acuerdo al género, entre otras cuestiones.

Sin embargo, cabe preguntarse si el derecho de opción establecido en la ley se enmarca dentro de las atribuciones privativas del Congreso Nacional de establecer el régimen jubilatorio o si, por el contrario, se vincula con el régimen de permanencia docente, invadiendo entonces esa potestad de las universidades nacionales. En suma, adelanto alguna de las conclusiones del presente trabajo: la opción de continuidad plasmada en la ley vulnera la autonomía universitaria, ya que nada tiene que ver con el beneficio de la jubilación y, por esa razón, es inconstitucional ${ }^{62}$.

desplegarse con mayor intensidad el principio de la autonomía, lo que importa sustraer la cuestión del ámbito de competencias del Congreso, quien por lo tanto no puede atribuirla a ningún otro órgano estatal" (Disidencia parcial del Dr. Carlos S. Fayt).

60 En esta orden de ideas, el Estatuto de la Universidad de Buenos Aires dispone que "El Ilamado a concurso periódico para el nombramiento de los profesores regulares tiene por objeto crear un ambiente que estimule la más intensa actividad intelectual y la mayor preocupación por la eficacia de la enseñanza" (art. 45).

61 “Art. 14 bis: El Estado otorgará los beneficios de la seguridad social, que tendrá carácter de integral e irrenunciable. En especial, la ley establecerá: el seguro social obligatorio, que estará a cargo de entidades nacionales o provinciales con autonomía financiera y económica, administradas por los interesados con participación del Estado, sin que pueda existir superposición de aportes; jubilaciones y pensiones móviles...".

62 Recientemente, el 19 de marzo de 2018, en la causa "Universidad de Buenos Aires c/Estado Nacional - Ministerio de Trabajo - Resolución n³3/09 s/ Proceso de Conocimiento", el 
Nótese que el artículo 51 del Estatuto no contiene disposiciones de índole previsional y que la limitación temporal en la función docente tiene como objeto la renovación periódica por concurso de los hombres y mujeres a cargo de la enseñanza. Sobre esta finalidad, Alterini resalta las ideas expresadas por los estudiantes reformistas de 1918, al reseñar las proclamas de la época:
Abogamos por la continua renovación del profesorado para que la enseñanza se suministre siempre según las nuevas corrientes y las modernas concepciones y porque queremos que no se favorezca la inercia de la cátedra y que ella esté desempeñada en todo momento por los mejores (Acta $\mathrm{n}^{\circ} 6$ de FUA, 1918). ${ }^{63}$

De hecho, cabe advertir que el Estatuto no formula un distingo etario entre varones y mujeres al momento de fijar el cese de la actividad docente, como sí lo hace la legislación de la seguridad social al puntualizar la edad jubilatoria.

Otro punto que evidencia que el régimen de permanencia no puede ser equiparado a la regulación jubilatoria es la circunstancia de que la legislación establece las condiciones de acceso a los beneficios de la seguridad social para cualquier docente universitario sin importar la categoría que revista. Por el contrario, de acuerdo al Estatuto universitario, sólo pueden acceder al rango de profesores consultos o eméritos los profesores regulares de 65 años, es decir, aquellos que deben su designación a un concurso de antecedentes y oposición.

Sobre esta cuestión, resulta esclarecedor trazar una analogía con el régimen de permanencia en el cargo y las jubilaciones de los jueces que integran el Poder Judicial de la Nación. Por una

titular del Juzgado Contencioso Administrativo Federal n 1, Juez Ernesto Marinelli, falló en sentido contrario a las ideas de este trabajo, al declarar la inconstitucionalidad de la resolución del Consejo Superior 2067/11 en el entendimiento que restringe en forma irrazonable los beneficios previsionales de la L. 26.508.

63 Alterinl, ob. cit., p. 141. 
parte, la $\mathrm{CN}$-en su art. 99, inc. $4^{64}$ - establece que los jueces de la CSJN y los magistrados de los tribunales federales inferiores duran en sus cargos hasta los 75 años. Luego de esa edad pueden continuar desempeñando funciones si el Senado les presta un nuevo acuerdo. Por otra parte, la Ley $24.018^{65}$ dispone que los jueces tienen el derecho a jubilarse a los 60 años, habiendo cumplido ciertos años de servicios y de aportes. De lo expuesto se pueden extraer las siguientes conclusiones: 1) que el poder constituyente reformador reguló el régimen de permanencia mientras que el Congreso estableció el sistema jubilatorio; 2) que estamos en presencia de cuestiones diferentes; 3) que la edad para ejercer el cargo no puede ser equiparada a la edad jubilatoria en el caso de los jueces, y 4) que, si la ley modificara el régimen de permanencia, sería inconstitucional ya que invadiría un ámbito que no es de su competencia.

Retomando, la regulación estatutaria persigue la renovación periódica del claustro docente por concursos. Para ello establece un tope etario de 65 años, el cual no resulta irrazonable ya que se adecua al estándar de retiro de la mayoría de las legislaciones, pero a su vez permite que los profesores con condiciones sobresalientes puedan continuar como consultos o eméritos al ser designados por los órganos democráticos. El acierto o desacierto del régimen de permanencia establecido por la Universidad de Buenos Aires no es susceptible de impugnación judicial, en el sentido de que “... no cabe a los tribunales examinar la

\footnotetext{
64 "Art. 99 inc.4: Nombra los magistrados de la Corte Suprema con acuerdo del Senado por dos tercios de sus miembros presentes, en sesión pública, convocada al efecto. Nombra los demás jueces de los tribunales federales inferiores en base a una propuesta vinculante en terna del Consejo de la Magistratura, con acuerdo del Senado, en sesión pública, en la que se tendrá en cuenta la idoneidad de los candidatos. Un nuevo nombramiento, precedido de igual acuerdo, será necesario para mantener en el cargo a cualquiera de esos magistrados, una vez que cumplan la edad de setenta y cinco años. Todos los nombramientos de magistrados cuya edad sea la indicada o mayor se harán por cinco años, y podrán ser repetidos indefinidamente, por el mismo trámite". Esta disposición fue introducida en la última reforma constitucional y dio lugar a los precedentes "Fayt" y "Schiffrin".
}

65 Sancionada el 13/11/1991 y promulgada parcialmente el 9/12/1991. 
oportunidad, mérito o conveniencia de los actos administrativos que hacen al gobierno y autonomía universitaria, sino que sólo pueden revisarse cuestiones atinentes a su legalidad" 66 .

Para concluir el análisis, de acuerdo al principio de competencia el orden jerárquico se configura de la siguiente manera:

a) Régimen jubilatorio (competencia exclusiva del Congreso)

1. La CN / Los tratados de derechos humanos con jerarquía constitucional.

2. Las leyes dictadas de conformidad con el artículo 14 bis, CN.

b) Régimen de permanencia (competencia exclusiva de la universidad)

1. La CN / Los tratados de derechos humanos con jerarquía constitucional.

2. Estatuto universitario.

Cabe advertir que este panorama se corresponde con los escenarios planteados en el capítulo anterior, en el sentido de que la temática determina el sujeto titular de la atribución normativa y, en consecuencia, distintos órdenes jerárquicos. En el caso de la edad jubilatoria, el órgano competente para obrar es el Congreso y en el caso de la edad de permanencia lo es la Universidad de Buenos Aires. En el primer tema la ley se posiciona por encima del Estatuto y en el segundo, de manera inversa.

\section{2. Ley estatal compatible con la autonomía universitaria}

En la causa "Universidad Nacional de Córdoba c/Estado Nacional - Ministerio de Trabajo y S.S. s/Acción Declarativa Art. 322 CPCC" ${ }^{\prime 67}$ (2010), se discutió la constitucionalidad y la aplicabilidad de la Ley 24.308, modificatoria del Decreto-ley

66 CSJN, “González de Delgado, Cristina y otros c/Universidad Nacional de Córdoba" (2000), Fallos: 323: 2659.

67 Fallos: 333: 1951. 
22.431, de protección a los discapacitados. El caso se inició con la acción declarativa de certeza deducida por la Universidad Nacional de Córdoba, a fin de que se declarase la inconstitucionalidad e inaplicabilidad de las normas señaladas, con fundamento en que resultaban violatorias de la autonomía universitaria.

El artículo 1 de la Ley $24.308^{68}$, titulada "Discapacitados", modificó el artículo 11 del Decreto-ley $22.431^{69}$ denominado "Sistema de protección integral de los discapacitados":

El Estado Nacional, los entes descentralizados y autárquicos, las empresas mixtas y del Estado y la Municipalidad de la Ciudad de Buenos Aires están obligados a otorgar en concesión, a personas con discapacidad, espacios para pequeños comercios en toda sede administrativa. Se incorporarán a este régimen las empresas privadas que brinden servicios públicos. Será nula de nulidad absoluta la concesión adjudicada sin respetar la obligatoriedad establecida en el presente artículo. El Ministerio de Trabajo y Seguridad Social, de oficio o a petición de parte, requerirá la revocación, por ilegítima, de tal concesión.

Esta norma fue reglamentada por el Decreto 795/94, del 23/5/1994, cuyo artículo 1 dispuso lo siguiente:

Quedan incluidos en el régimen del artículo 11 de la Ley $\mathrm{n}^{\circ} 22.431$, sustituido por el artículo $1^{\circ}$ de la Ley $\mathrm{n}^{\mathrm{o}} 24.308$, todos los organismos del Estado Nacional y de la Municipalidad de la Ciudad de Buenos Aires, cualquiera fuere su naturaleza jurídica y la función que desempeñaren (Ministerios, Secretarías, entes descentralizados o autárquicos, empresas del Estado o de economía mixta, establecimientos sanitarios y educacionales de todos los niveles, obras sociales, etc.). Asimismo, quedan comprendidos en dicha norma todas las entidades o establecimientos privados que presten servicios públicos,

68 Sancionada el 23/12/1993 y promulgada el 11/1/1994.

69 Sancionado y promulgado el 16/3/1981. 
tales como teléfono, energía eléctrica, gas, agua corriente, transporte terrestre, aéreo, marítimo o fluvial, asistencia sanitaria o educacional de todos los niveles, etc., así como también las obras sociales de los diversos sectores privados. En ambos casos la obligación impuesta por la ley deberá ser cumplida siempre que se trate de organismos, entidades o establecimientos a los que concurra diariamente un promedio de trescientas (300) personas como mínimo.

En resumen, de acuerdo a las disposiciones citadas, las universidades nacionales están obligadas a otorgar en concesión un espacio para pequeños comercios a personas con discapacidad.

Planteada la cuestión, corresponde en adelante determinar si las normas dictadas por el Congreso Nacional, en resguardo de las personas con discapacidad, invaden la autonomía universitaria. En este sentido, no se puede obviar que la Convención sobre los Derechos de las Personas con Discapacidad ${ }^{70}$ contiene disposiciones que obligan al Estado a adoptar medidas en pos de la inclusión social y la no discriminación. En materia de trabajo y empleo ${ }^{71}$, la Convención compromete a los poderes

70 Esta convención entró en vigor en el 2008, mediante la L. 26.378 y adquirió jerarquía constitucional en el 2014 con la L. 27.044.

71 "Art. 27: Trabajo y empleo 1. Los Estados Partes reconocen el derecho de las personas con discapacidad a trabajar, en igualdad de condiciones con las demás; ello incluye el derecho a tener la oportunidad de ganarse la vida mediante un trabajo libremente elegido 0 aceptado en un mercado y un entorno laborales que sean abiertos, inclusivos y accesibles a las personas con discapacidad. Los Estados Partes salvaguardarán y promoverán el ejercicio del derecho al trabajo, incluso para las personas que adquieran una discapacidad durante el empleo, adoptando medidas pertinentes, incluida la promulgación de legislación, entre ellas: a) Prohibir la discriminación por motivos de discapacidad con respecto a todas las cuestiones relativas a cualquier forma de empleo, incluidas las condiciones de selección, contratación y empleo, la continuidad en el empleo, la promoción profesional y unas condiciones de trabajo seguras y saludables; b) Proteger los derechos de las personas con discapacidad, en igualdad de condiciones con las demás, a condiciones de trabajo justas y favorables, y en particular a igualdad de oportunidades y de remuneración por trabajo de igual valor, a condiciones de trabajo seguras y saludables, incluida la protección contra el acoso, y a la reparación por agravios sufridos; c) Asegurar que las personas con discapacidad puedan ejercer sus derechos laborales y sindicales, en igualdad de condiciones con las demás; d) Permitir que 
estatales a generar políticas de empleo en el sector público. El incumplimiento de tal Convención acarrea la responsabilidad internacional del Estado. Sobre este punto, la Convención Americana de Derechos Humanos contiene una disposición referida a las obligaciones que asumen los Estados federales por los miembros que la componen. Así, en su artículo 28, titulado "Cláusula Federal", se establece lo siguiente:

1. Cuando se trate de un Estado parte constituido como Estado Federal, el gobierno nacional de dicho Estado parte cumplirá todas las disposiciones de la presente Convención relacionadas con las materias sobre las que ejerce jurisdicción legislativa y judicial. 2. Con respecto a las disposiciones relativas a las materias que corresponden a la jurisdicción de las entidades componentes de la federación, el gobierno nacional debe tomar de inmediato las medidas pertinentes, conforme a su constitución y sus leyes, a fin de que las autoridades competentes de dichas entidades puedan adoptar las disposiciones del caso para el cumplimiento de esta Convención. 3. Cuando dos o más Estados Partes acuerden integrar entre sí una federación u otra clase de asociación, cuidarán de que el pacto comunitario correspondiente contenga las disposiciones necesarias para que continúen haciéndose

las personas con discapacidad tengan acceso efectivo a programas generales de orientación técnica y vocacional, servicios de colocación y formación profesional y continua; e) Alentar las oportunidades de empleo y la promoción profesional de las personas con discapacidad en el mercado laboral, y apoyarlas para la búsqueda, obtención, mantenimiento del empleo y retorno al mismo; f) Promover oportunidades empresariales, de empleo por cuenta propia, de constitución de cooperativas y de inicio de empresas propias; g) Emplear a personas con discapacidad en el sector público; h) Promover el empleo de personas con discapacidad en el sector privado mediante políticas y medidas pertinentes, que pueden incluir programas de acción afirmativa, incentivos y otras medidas; i) Velar por que se realicen ajustes razonables para las personas con discapacidad en el lugar de trabajo; j) Promover la adquisición por las personas con discapacidad de experiencia laboral en el mercado de trabajo abierto; k) Promover programas de rehabilitación vocacional y profesional, mantenimiento del empleo y reincorporación al trabajo dirigidos a personas con discapacidad. 2. Los Estados Partes asegurarán que las personas con discapacidad no sean sometidas a esclavitud ni servidumbre y que estén protegidas, en igualdad de condiciones con las demás, contra el trabajo forzoso u obligatorio". 
efectivas en el nuevo Estado así organizado, las normas de la presente Convención.

Si bien la cláusula hace referencia a los Estados parte de la Federación, se aplica a todo el universo estatal, razón por la cual las universidades públicas están obligadas por la normativa convencional. En la misma sintonía, el artículo 75, inciso 23, $\mathrm{CN}$, obliga al Congreso Nacional a promover medidas de acción positiva respecto de las personas con discapacidad ${ }^{72}$.

La CSJN resolvió el caso -haciendo suyos los fundamentos y conclusiones de la Procuración General- estableciendo que las normas sobre discapacidad dictadas por el Congreso Nacional no invaden la autonomía y, por lo tanto, son aplicables al ámbito de las universidades nacionales. Entre los argumentos principales de la sentencia cabe destacar los siguientes:

Las universidades deben disponer de las potestades necesarias para llevar a cabo su gestión respetando su contenido esencial, constituido básicamente por todos los elementos necesarios que hacen al aseguramiento de la libertad académica y la libertad de cátedra. Sin embargo, la facultad de dictar sus normas de funcionamiento interno, en particular aquellas que se vinculan al modo de administrar sus fondos, no puede en modo alguno convertirse en un obstáculo al ejercicio de las potestades que la Constitución confiere al Congreso para adoptar medidas que garanticen el pleno goce y ejercicio de derechos reconocidos por la Ley fundamental (art. 75, inc. 23) y los tratados internacionales por parte de las personas con discapacidad, materia que, sin duda, está librada a la discrecionalidad del legislador.

(...)

No importa un avasallamiento de la autonomía universitaria ni de la autarquía económico-financiera de la que

72 “Art. 75, inc. 23: (...) Legislar y promover medidas de acción positiva que garanticen la igualdad real de oportunidades y de trato, y el pleno goce y ejercicio de los derechos reconocidos por esta Constitución y por los tratados internacionales vigentes sobre derechos humanos, en particular respecto de los niños, las mujeres, los ancianos y las personas con discapacidad". 
gozan, pues del mismo modo que las instituciones universitarias nacionales ejercen la autarquía dentro del régimen de la ley $\mathrm{n}^{\circ} 24.156$ y aplican el régimen general de contrataciones, de responsabilidad patrimonial y de gestión de bienes reales (art. 59 de la ley $\mathrm{n}^{\circ} 24.521$ ), no se advierten razones válidas que permitan sustraerlas de un sistema de protección de las personas con discapacidad, cuyo ámbito de aplicación fue definido claramente por el legislador. (...)

Si bien las instituciones universitarias nacionales están en libertad de regular la generación de recursos adicionales, deben ejercer tal potestad en el marco jurídico que establecen la Constitución y la ley, circunstancia que impide considerar que la aplicación de ordenamientos que establecen una protección especial para personas discapacitadas en el ámbito universitario afecte el contenido esencial de la autonomía consagrada por el art. 75, inc. 19, de la Constitución Nacional, conclusión que no implica la obligación automática de entregar en concesión espacios para pequeños comercios a todo aquel que lo peticione, sino que las autoridades universitarias deben cumplir el deber legal en los casos previstos en las normas ejerciendo sus atribuciones discrecionales al escoger a la persona discapacitada que se hará cargo del pequeño comercio.

En definitiva, la CSJN consideró que la aplicación de las normas de protección de las personas con discapacidad en las universidades no constituye un atropello al contenido de la autonomía, toda vez que es potestad del Congreso Nacional adoptar medidas para tutelar los derechos fundamentales.

En lo que tiene que ver con el plano de la operatividad de los derechos, la CSJN, en el caso "Biasizo Rogelio José c/UTN s/Empleo Público"73 (2017), sostuvo:

Si bien es razonable que las universidades puedan disponer de las potestades necesarias para llevar a cabo su

73 Fallos: 340: 983. 
gestión respetando su contenido esencial, constituido básicamente por todos los elementos necesarios que hacen al aseguramiento de la libertad académica y la libertad de cátedra, la facultad de dictar sus normas de funcionamiento interno no puede en modo alguno convertirse en un obstáculo al ejercicio de los derechos consagrados por la Constitución Nacional.

Sin lugar a dudas, la obligación establecida en el Pacto de San José ${ }^{74}$ de respetar y hacer efectivos los derechos fundamentales alcanza a las universidades, al igual que a los Estados, toda vez que son parte del entramado institucional.

En síntesis, respecto de la materia aquí tratada, el orden de prelación es el siguiente:

1. La CN / Los tratados de derechos humanos con jerarquía constitucional (en particular la Convención sobre los derechos de las personas con discapacidad).

2. Las leyes dictadas de conformidad con el artículo 75 , incisos 18, 19 y 24, CN.

3. Los estatutos universitarios.

\section{3. Una variedad de situaciones}

Luego de analizar los casos anteriores, me interesa poner de relieve la multiplicidad de situaciones que pueden darse en cuanto a la interpretación de la autonomía de las universidades

\footnotetext{
74 "Art. 1: Obligación de Respetar los Derechos. 1. Los Estados Partes en esta Convención se comprometen a respetar los derechos y libertades reconocidos en ella y a garantizar su libre y pleno ejercicio a toda persona que esté sujeta a su jurisdicción, sin discriminación alguna por motivos de raza, color, sexo, idioma, religión, opiniones políticas o de cualquier otra índole, origen nacional o social, posición económica, nacimiento o cualquier otra condición social. 2. Para los efectos de esta Convención, persona es todo ser humano.

Art. 2. Deber de Adoptar Disposiciones de Derecho Interno. Si el ejercicio de los derechos y libertades mencionados en el artículo 1 no estuviere ya garantizado por disposiciones legislativas o de otro carácter, los Estados Partes se comprometen a adoptar, con arreglo a sus procedimientos constitucionales y a las disposiciones de esta Convención, las medidas legislativas o de otro carácter que fueren necesarias para hacer efectivos tales derechos y libertades".
} 


\section{nacionales. A continuación, expongo un cuadro que refleja la diversidad de temas tratados por la CSJN.}

\begin{tabular}{|c|c|c|}
\hline \multicolumn{3}{|c|}{ JURISPRUDENCIA DE LA CORTE SUPREMA DE JUSTICIA DE LA NACIÓN } \\
\hline TEMA & CASO & OPINIÓN \\
\hline \multirow[t]{3}{*}{$\begin{array}{l}\text { Integración } \\
\text { de los } \\
\text { órganos de } \\
\text { gobierno }\end{array}$} & \multirow[t]{2}{*}{$\begin{array}{l}\text { Estado Nacional } \\
\text { (Ministerio de } \\
\text { Cultura y Educa- } \\
\text { ción) c/Universidad } \\
\text { Nacional de Luján } \\
\text { s/aplicación Ley } \\
24521 \\
\text { E. 9. XXXIII. } \\
\text { REX27/05/1999 } \\
\text { Fallos: 322:842 }\end{array}$} & $\begin{array}{l}\text { "La delimitación del modo de integración de los órga- } \\
\text { nos de la universidad no afecta el contenido esencial } \\
\text { de la autonomía, sino que está dirigida a garantizar } \\
\text { la representación de los distintos estamentos } \\
\text { universitarios mediante una norma que asegura una } \\
\text { posición predominante a los profesores, de modo que } \\
\text { la libertad de actividad científica no se vea perturbada } \\
\text { por la actuación de otros estamentos". }\end{array}$ \\
\hline & & $\begin{array}{l}\text { "Corresponde declarar la inconstitucionalidad de las } \\
\text { previsiones legales que establecen detalladamente } \\
\text { la forma en que los estatutos deben disponer la com- } \\
\text { posición de los órganos de gobierno y control interno. } \\
\text { Ello es así pues - más allá de que las previsiones de la } \\
\text { ley puedan responder a nobles objetivos, tales como } \\
\text { asegurar la transparencia del sistema, la integración } \\
\text { democrática y plural de los órganos de gobierno- en } \\
\text { un régimen de autonomía la regulación de estos as- } \\
\text { pectos corresponde al ente autónomo, sin perjuicio de } \\
\text { su cuestionamiento por la vía y forma que corresponda } \\
\text { (Disidencia parcial del Dr. Carlos S. Fayt)". }\end{array}$ \\
\hline & $\begin{array}{l}\text { Molina, José Luis } \\
\text { c/Universidad } \\
\text { Nacional } \\
\text { de Catamarca. } \\
\text { M. 922. XXX- } \\
\text { VI.24/04/2003 } \\
\text { Fallos: } 326: 1389\end{array}$ & $\begin{array}{l}\text { "La fijación de porcentajes mínimos de integración de } \\
\text { los diferentes claustros en los órganos de gobierno de } \\
\text { la universidad no importa inmiscuirse en la potestad } \\
\text { normativa de la misma ni afecta el contenido esencial } \\
\text { de la autonomía, sino que está dirigida a garantizar } \\
\text { la representación de los distintos estamentos } \\
\text { universitarios mediante una norma que asegura una } \\
\text { posición predominante a los profesores de modo que } \\
\text { la libertad de actividad científica no se vea perturbada } \\
\text { por la actuación de otros estamentos. (Del dictamen } \\
\text { de la Procuración General, al que remitió la Corte } \\
\text { Suprema)". }\end{array}$ \\
\hline
\end{tabular}




\begin{tabular}{|c|c|c|}
\hline TEMA & CASO & OPINIÓN \\
\hline $\begin{array}{l}\text { Inte- } \\
\text { gración } \\
\text { de los } \\
\text { órganos } \\
\text { de } \\
\text { gobierno }\end{array}$ & $\begin{array}{l}\text { Ministerio de } \\
\text { Cultura y Educa- } \\
\text { ción de la Nación } \\
\text { c/Universidad } \\
\text { Nacional de La } \\
\text { Plata s/inf. Ley } \\
\text { 24521 art. } 34 \\
\text { M. 910. XLVI. } \\
\text { REX16/02/2016 } \\
\text { Fallos: 339:115 }\end{array}$ & $\begin{array}{l}\text { “Una interpretación razonable y armónica de la ley } \\
\text { permite concluir que la prohibición que surge del } \\
\text { art. } 53 \text {, inc. d) de la ley } 24.521 \text { de Educación Supe- } \\
\text { rior sólo se dirige a limitar la participación en los } \\
\text { órganos de gobierno de los graduados en relación } \\
\text { de dependencia con la universidad, a los fines de la } \\
\text { representación de su claustro en el carácter que les } \\
\text { es propio, esto es, el de graduados, pero nada dice } \\
\text { respecto del agrupamiento de los representantes } \\
\text { de diferentes estamentos y la conformación de } \\
\text { los padrones, cuestiones previstas por las normas } \\
\text { impugnadas del estatuto (arts. } 88 \text {, inc. } 4^{\circ} \text { y } 94 \text {, } \\
2^{\circ} \text { párrafo)". }\end{array}$ \\
\hline $\begin{array}{l}\text { Carga } \\
\text { horaria } \\
\text { docente }\end{array}$ & $\begin{array}{l}\text { Biasizo, Rogelio } \\
\text { José c/ UTN } \\
\text { s/empleo público } \\
\text { CAF } \\
\text { 017662/2011/ } \\
\text { CS00110/08/2017 } \\
\text { Fallos: 340:983 }\end{array}$ & $\begin{array}{l}\text { "La regulación de las incompatibilidades del } \\
\text { personal docente de las universidades nacionales } \\
\text { mediante el convenio colectivo de trabajo que el } \\
\text { Poder Ejecutivo homologó por el decreto 1470/98 } \\
\text { no parece entrañar una afectación de la autonomía } \\
\text { universitaria, ni una limitación a su potestad regu- } \\
\text { latoria, puesto que, en definitiva, permite que cada } \\
\text { universidad establezca su propio régimen y sólo fija } \\
\text { la máxima carga horaria que se le puede adjudicar } \\
\text { a un docente con miras a un óptimo desempeño } \\
\text { académico. (Del dictamen de la Procuración General } \\
\text { al que la Corte remite)". }\end{array}$ \\
\hline $\begin{array}{l}\text { Régimen } \\
\text { de } \\
\text { adminis- } \\
\text { tración de } \\
\text { personal }\end{array}$ & $\begin{array}{l}\text { Ryser, Walter } \\
\text { Adolfo c/ Univer- } \\
\text { sidad Nacional de } \\
\text { Catamarca s/ } \\
\text { apelación art. } 32 \\
\text { Ley } 24521 \\
\text { R. } 512 . \text { XLIX. } \\
\text { RHE03/05/2017 } \\
\text { Fallos: } 340: 614\end{array}$ & $\begin{array}{l}\text { "La Universidad Nacional de Catamarca, en su } \\
\text { carácter de institución universitaria nacional, es una } \\
\text { persona jurídica de derecho público con autonomía } \\
\text { académica y autarquía económica y financiera } \\
\text { (art. } 75 \text {, inc. } 19 \text { de la Constitución Nacional), corres- } \\
\text { pondiéndole, según lo establecido por el art. } 59 \text { de } \\
\text { la ley 24.521, fijar su régimen de administración de } \\
\text { personal. (Del dictamen de la Procuración General al } \\
\text { que la Corte remite)". }\end{array}$ \\
\hline
\end{tabular}




\begin{tabular}{|c|c|c|}
\hline \multicolumn{3}{|c|}{ JURISPRUDENCIA DE LA CORTE SUPREMA DE JUSTICIA DE LA NACIÓN } \\
\hline TEMA & CASO & OPINIÓN \\
\hline $\begin{array}{l}\text { Régimen } \\
\text { de adminis- } \\
\text { tración de } \\
\text { personal }\end{array}$ & $\begin{array}{l}\text { Franchini Rafael } \\
\text { Luis Hoy Jerosimich } \\
\text { Margarita c/ } \\
\text { resol. n³20/03 del } \\
\text { Consejo Sup. de la } \\
\text { UNNE s/recurso de } \\
\text { apelación art. } 32 \text { de } \\
\text { la Ley 24521 } \\
\text { F. 156. XLV. } \\
\text { ROR04/09/2012 } \\
\text { Fallos: 335:1655 }\end{array}$ & $\begin{array}{l}\text { “Cabe confirmar la sentencia que anuló la resolución } \\
\text { del Consejo Superior de la Universidad del Nordeste, } \\
\text { mediante la cual se había dispuesto que los decretos } \\
894 / 01 \text { y 946/01-que establecían la incompatibi- } \\
\text { lidad entre el cobro de un haber previsional y una } \\
\text { remuneración por cargo en la función pública- eran } \\
\text { aplicables al ámbito de esa universidad, pues dicha } \\
\text { decisión, lejos de cercenar la autonomía universitaria, } \\
\text { la asegura al resolver que no se aplique en su ámbito } \\
\text { un régimen destinado a regir al personal de la Admi- } \\
\text { nistración central. (Del dictamen de la Procuración } \\
\text { General, al que remitió la Corte Suprema)". }\end{array}$ \\
\hline \multirow[t]{2}{*}{$\begin{array}{l}\text { Integración } \\
\text { de los } \\
\text { jurados } \\
\text { de los } \\
\text { concursos }\end{array}$} & $\begin{array}{l}\text { Mocchiutti, Juan } \\
\text { c/ UNC. s/ } \\
\text { contencioso- } \\
\text { administrativo } \\
\text { M. } 884 . \\
\text { XXIII.04/11/1997 } \\
\text { Fallos: } 320: 2298\end{array}$ & $\begin{array}{l}\text { "Aunque en determinadas condiciones los alumnos y } \\
\text { egresados participen en las decisiones de la univer- } \\
\text { sidad, ello no autoriza a trasladar sin limitaciones el } \\
\text { principio de cogobierno universitario al ámbito acadé- } \\
\text { mico, otorgándole a su intervención en los concursos } \\
\text { docentes carácter decisorio, pues ello desnaturaliza la } \\
\text { finalidad del Estatuto de la Universidad Nacional de } \\
\text { Córdoba". }\end{array}$ \\
\hline & $\begin{array}{l}\text { Ministerio de Edu- } \\
\text { cación de la Nación } \\
\text { c/Universidad Nac. } \\
\text { del Noroeste de } \\
\text { la Prov. de Bs. As. } \\
\text { s/recurso adminis- } \\
\text { trativo directo } \\
\text { M. } 976 \text {. XLV. } \\
\text { REX11/12/2014 }\end{array}$ & $\begin{array}{l}\text { "Las previsiones del Estatuto de la Universidad } \\
\text { Nacional del Noroeste de la Provincia de Buenos } \\
\text { Aires (UNNOBA) que contemplan la participación } \\
\text { de un estudiante en los jurados docentes en iguales } \\
\text { condiciones que los otros miembros (profesores } \\
\text { por concurso o personas que sin serlo cuenten con } \\
\text { idoneidad indiscutible) y establecen que aquél tenga } \\
\text { aprobadas las materias del área que se concursa y } \\
\text { cumpla con las condiciones requeridas para integrar } \\
\text { el claustro, se presentan incompatibles con los } \\
\text { principios de organización de la educación superior. } \\
\text { (Del dictamen de la Procuración General al que la } \\
\text { Corte remite)". }\end{array}$ \\
\hline
\end{tabular}




\begin{tabular}{|c|c|c|}
\hline \multicolumn{3}{|c|}{ JURISPRUDENCIA DE LA CORTE SUPREMA DE JUSTICIA DE LA NACIÓN } \\
\hline TEMA & CASO & OPINIÓN \\
\hline $\begin{array}{l}\text { Integración } \\
\text { de los } \\
\text { jurados } \\
\text { de los } \\
\text { concursos }\end{array}$ & $\begin{array}{l}\text { Ministerio de Edu- } \\
\text { cación de la Nación } \\
\text { c/Universidad Nac. } \\
\text { del Noroeste de } \\
\text { la Prov. de Bs. As. } \\
\text { s/recurso adminis- } \\
\text { trativo directo } \\
\text { M. 976. XLV. } \\
\text { REX11/12/2014 }\end{array}$ & $\begin{array}{l}\text { "Corresponde confirmar la sentencia que rechazó las } \\
\text { observaciones a los arts. } 24 \text { y } 25 \text { del Estatuto de la } \\
\text { Universidad Nacional del Noroeste de la Provincia } \\
\text { de Buenos Aires que contemplan que un estudiante } \\
\text { que tenga aprobadas las materias del área que se } \\
\text { concursa y cumpla con las condiciones requeridas } \\
\text { para integrar el claustro forme parte del jurado para } \\
\text { sustanciar los concursos docentes, ya que siendo los } \\
\text { estudiantes sujetos pasivos del derecho de aprender } \\
\text { y con derecho a educarse y a elegir la educación } \\
\text { impartida, no se muestra irrazonable que quienes } \\
\text { tienen el derecho de educarse y de elegir la educación } \\
\text { impartida, participen en alguna medida -mínima } \\
\text { en este caso- en el criterio de selección de los } \\
\text { aspirantes a ejercer las funciones de las que luego } \\
\text { serán destinatarios. (Disidencia de los Dres. E. Raúl } \\
\text { Zaffaroni y Carlos S. Fayt)". }\end{array}$ \\
\hline \multirow[t]{2}{*}{$\begin{array}{l}\text { Autarquía } \\
\text { económico- } \\
\text { financiera }\end{array}$} & $\begin{array}{l}\text { Estado Nacional } \\
\text { (Ministerio de } \\
\text { Cultura y Educa- } \\
\text { ción) c/Universidad } \\
\text { Nacional de Luján } \\
\text { s/aplicación ley } \\
24521 \\
\text { E. 9. XXXIII. } \\
\text { REX27/05/1999 } \\
\text { Fallos: 322:842 }\end{array}$ & $\begin{array}{l}\text { "Frente a los claros términos de la ley 24.156, a la } \\
\text { que remite el art. } 59 \text { de la Ley de Educación Superior, } \\
\text { resulta ilegítimo que la universidad pretenda, a través } \\
\text { de la norma estatutaria, sustraerse a la aplicación } \\
\text { de dicho régimen legal -al que obligatoriamente } \\
\text { debe someterse- limitando su sujeción a un aspecto } \\
\text { parcial de aquél como es la verificación posterior de la } \\
\text { realidad del gasto". }\end{array}$ \\
\hline & $\begin{array}{l}\text { Estado Nacional } \\
\text { - Ministerio de } \\
\text { Cultura y Educación } \\
\text { c/Universidad } \\
\text { Nacional de } \\
\text { General Sarmiento } \\
\text { s/recurso } \\
\text { E. 129. XL. } \\
\text { REX06/05/2008 }\end{array}$ & $\begin{array}{l}\text { "La decisión de dictar disposiciones respecto } \\
\text { del art. } 59 \text { de la ley } 24.521 \text {, que al referirse al } \\
\text { sostenimiento y régimen económico financiero, dispo- } \\
\text { ne que las universidades tienen autarquía económico } \\
\text { financiera y, en ese marco, el inc. c establece que } \\
\text { podrán dictar normas relativas a la generación de } \\
\text { recursos adicionales a los aportes del Tesoro Nacio- } \\
\text { nal, mediante la venta de bienes, productos, derechos } \\
\text { o servicios, subsidios, contribuciones, herencias, } \\
\text { derechos o tasas por los servicios que presten, así } \\
\text { como todo otro recurso que pudiera corresponderles } \\
\text { por cualquier título o actividad, queda en el ámbito de } \\
\text { la autonomía de la institución". }\end{array}$ \\
\hline
\end{tabular}




\begin{tabular}{|c|c|c|}
\hline \multicolumn{3}{|c|}{ JURISPRUDENCIA DE LA CORTE SUPREMA DE JUSTICIA DE LA NACIÓN } \\
\hline TEMA & CASO & OPINIÓN \\
\hline \multirow[t]{3}{*}{$\begin{array}{l}\text { Requisitos } \\
\text { de validez } \\
\text { para los } \\
\text { títulos }\end{array}$} & \multirow{3}{*}{$\begin{array}{l}\text { Universidad } \\
\text { Nacional de } \\
\text { Córdoba (doctor } \\
\text { Eduardo Humberto } \\
\text { Staricco - rector) } \\
\text { c/Estado Nacional } \\
\text {-declaración de } \\
\text { inconstitucionali- } \\
\text { dad- sumario. } \\
\text { U } 2 \\
\text { XXXIII27/05/1999 } \\
\text { Fallos: 322:919 }\end{array}$} & $\begin{array}{l}\text { "No resulta válido sostener que los arts. 29, inc. f), } \\
42 \text { y } 43 \text { de la ley } 24.521 \text { vulneren la autonomía } \\
\text { universitaria al otorgar al Ministerio de Cultura y } \\
\text { Educación, en coordinación con los órganos creados } \\
\text { al efecto, la fijación de requisitos de validez para los } \\
\text { títulos (carga horaria mínima, contenidos curriculares } \\
\text { básicos y criterios de intensidad de la práctica } \\
\text { profesional) cuando lo comprometido de modo directo } \\
\text { es el servicio educativo nacional". }\end{array}$ \\
\hline & & $\begin{array}{l}\text { "Corresponde admitir los cuestionamientos constitu- } \\
\text { cionales de los arts. } 42 \text { y } 43 \text { inc. a, de la ley } 24.521, \\
\text { pues tanto la carga horaria en los planes de estudio } \\
\text { y la fijación de los contenidos curriculares mínimos } \\
\text { resultan ajenas a las facultades del Congreso y } \\
\text { propias - dentro de un régimen de autonomía- preci- } \\
\text { samente de esos entes autónomos. (Disidencia parcial } \\
\text { del Dr. Carlos S. Fayt)". }\end{array}$ \\
\hline & & $\begin{array}{l}\text { "Por incurrir en avasallamiento del ámbito académico, } \\
\text { reservado a la universidad nacional, corresponde } \\
\text { declarar la inconstitucionalidad del art. } 42 \text { in fine, de } \\
\text { la ley } 24.521 \text { (carga horaria mínima); del art. } 43 \text {, inc. a } \\
\text { (injerencia del Ministerio de Cultura y Educación en la } \\
\text { definición de los contenidos curriculares y de criterios } \\
\text { sobre intensidad de la formación práctica); y del } \\
\text { art. 43, inc. b (régimen de "acreditación periódica" de } \\
\text { las carreras). (Disidencia parcial del Dr. Augusto César } \\
\text { Belluscio)". }\end{array}$ \\
\hline $\begin{array}{l}\text { Evalua- } \\
\text { ciones } \\
\text { externas }\end{array}$ & $\begin{array}{l}\text { Universidad } \\
\text { Nacional de } \\
\text { Córdoba (doctor } \\
\text { Eduardo Humberto } \\
\text { Staricco - rector) } \\
\text { c/ Estado Nacional } \\
\text {-declaración de } \\
\text { inconstitucionali- } \\
\text { dad- sumario. } \\
\text { U } 2 \\
\text { XXXIII27/05/1999 } \\
\text { Fallos: 322:919 }\end{array}$ & $\begin{array}{l}\text { "Las conclusiones que resulten de las evaluaciones } \\
\text { externas carecen de efectos vinculantes para las } \\
\text { universidades, en tanto la ley } 24.521 \text { prevé únicamen- } \\
\text { te que las recomendaciones para el mejoramiento } \\
\text { institucional que surjan de tales evaluaciones tendrán } \\
\text { estado público (art. 44)". }\end{array}$ \\
\hline
\end{tabular}




\begin{tabular}{|c|c|c|}
\hline \multicolumn{3}{|c|}{ JURISPRUDENCIA DE LA CORTE SUPREMA DE JUSTICIA DE LA NACIÓN } \\
\hline TEMA & CASO & OPINIÓN \\
\hline \multirow[t]{2}{*}{$\begin{array}{l}\text { Evalua- } \\
\text { ciones } \\
\text { externas }\end{array}$} & \multirow{2}{*}{$\begin{array}{l}\text { Universidad } \\
\text { Nacional de } \\
\text { Córdoba (doctor } \\
\text { Eduardo Humberto } \\
\text { Staricco - rector) } \\
\text { c/ Estado Nacional } \\
\text {-declaración de } \\
\text { inconstitucionali- } \\
\text { dad- sumario. } \\
\text { U } 2 \\
\text { XXXIII27/05/1999 } \\
\text { Fallos: 322:919 }\end{array}$} & $\begin{array}{l}\text { "Son inconstitucionales los arts. 43, inc. b, 44, } 45 \\
\text { y } 46 \text {, inc. b, de la ley } 24.521 \text {, en tanto pretenden } \\
\text { regular el control externo de la actividad docente } \\
\text { universitaria, pues constituyen una indebida injerencia } \\
\text { en el ámbito en el que precisamente debe reinar la } \\
\text { autonomía sin cortapisas, como es el estrictamente } \\
\text { académico. (Disidencia parcial del Dr. Carlos S. Fayt)". }\end{array}$ \\
\hline & & $\begin{array}{l}\text { "Corresponde declarar la invalidez constitucional del } \\
\text { art. } 44 \text { de la ley } 24.521 \text { en cuanto dispone evaluacio- } \\
\text { nes externas que abarcarán las funciones de docencia, } \\
\text { investigación y extensión y la gestión institucional de } \\
\text { las universidades nacionales. La circunstancia de que } \\
\text { estas evaluaciones finalicen en "recomendaciones" } \\
\text { públicas no convierte en meramente conjetural el } \\
\text { agravio, pues se ha plasmado una injerencia indebida } \\
\text { en el ámbito de autonomía de las universidades } \\
\text { nacionales que justifica tal descalificación, como } \\
\text { así también del art. } 46, \text { inc. b, de la mencionada ley, } \\
\text { en cuanto concierna a universidades nacionales. } \\
\text { (Disidencia parcial del Dr. Augusto César Belluscio)". }\end{array}$ \\
\hline $\begin{array}{l}\text { Ingreso a } \\
\text { la carrera } \\
\text { docente } \\
\text { mediante } \\
\text { concursos }\end{array}$ & $\begin{array}{l}\text { Universidad } \\
\text { Nacional de } \\
\text { Córdoba (doctor } \\
\text { Eduardo Humberto } \\
\text { Staricco - rector) } \\
\text { c/Estado Nacional } \\
\text {-declaración de } \\
\text { inconstitucionali- } \\
\text { dad- sumario. } \\
\text { U } 2 \\
\text { XXXIII27/05/1999 } \\
\text { Fallos: 322:919 }\end{array}$ & $\begin{array}{l}\text { "El art. } 51 \text { de la Ley de Educación Superior no vulnera } \\
\text { la autonomía universitaria en la medida en que hace } \\
\text { al diseño de la organización educativa, que compete } \\
\text { al Congreso en uso de las facultades conferidas por } \\
\text { el art. 75, inc. 18, de la Constitución Nacional, sin que } \\
\text { sustraiga a las instituciones universitarias - por ser } \\
\text { competencia propia y exclusiva de ellas- la facultad } \\
\text { de efectuar la selección y designación de su personal } \\
\text { docente". }\end{array}$ \\
\hline $\begin{array}{l}\text { Comunica- } \\
\text { ción de los } \\
\text { estatutos } \\
\text { al Poder } \\
\text { Ejecutivo }\end{array}$ & $\begin{array}{l}\text { Estado Nacional } \\
\text { (Ministerio de } \\
\text { Cultura y Educa- } \\
\text { ción) c/Universidad } \\
\text { Nacional de Luján } \\
\text { s/aplicación ley } \\
24.521 \\
\text { E. 9. XXXIII. } \\
\text { REX27/05/1999 } \\
\text { Fallos: } 322: 842\end{array}$ & $\begin{array}{l}\text { "El juego armónico de los arts. } 34 \text { y } 79 \text { de la ley } \\
24.521 \text { deja al descubierto que la comunicación de } \\
\text { los estatutos al ministerio y la posibilidad de que el } \\
\text { Estado Nacional, por su intermedio, los cuestione } \\
\text { judicialmente, no viola en modo alguno la autonomía } \\
\text { universitaria consagrada por la Constitución Nacional, } \\
\text { desde que no escapa a la jurisdicción del Poder } \\
\text { Judicial ninguno de los problemas jurídico } \\
\text {-institucionales que se puedan suscitar en la universi- } \\
\text { dad. (Disidencia parcial del Dr. Carlos S. Fayt)". }\end{array}$ \\
\hline
\end{tabular}




\begin{tabular}{|c|c|c|}
\hline \multicolumn{3}{|c|}{ JURISPRUDENCIA DE LA CORTE SUPREMA DE JUSTICIA DE LA NACIÓN } \\
\hline TEMA & CASO & OPINIÓN \\
\hline \multirow[t]{4}{*}{$\begin{array}{l}\text { Control de } \\
\text { los actos } \\
\text { de las } \\
\text { Universida- } \\
\text { des }\end{array}$} & $\begin{array}{l}\text { González de } \\
\text { Delgado, Cristina y } \\
\text { otros c/Universidad } \\
\text { Nacional de } \\
\text { Córdoba. } \\
\text { G } 653 \\
\text { XXXIII19/09/2000 } \\
\text { Fallos: 323:2659 } \\
\end{array}$ & $\begin{array}{l}\text { "Sentada la competencia del Consejo Superior de la } \\
\text { Universidad de Córdoba para dictar la Ordenanza 2/97, } \\
\text { por la que se transformó al Colegio Nacional de Mon- } \\
\text { serrat en un establecimiento de educación mixta, no } \\
\text { cabe a los tribunales examinar la oportunidad, mérito } \\
\text { o conveniencia de los actos administrativos que hacen } \\
\text { al gobierno y autonomía universitaria, sino que sólo } \\
\text { pueden revisarse cuestiones atinentes a su legalidad". }\end{array}$ \\
\hline & $\begin{array}{l}\text { Tandecarz, } \\
\text { Juana Sara y otros } \\
\text { c/Universidad de } \\
\text { Buenos Aires. } \\
\text { T. } 171 . \\
\text { XXXIV.02/07/2002 } \\
\text { Fallos: } 325: 1676\end{array}$ & $\begin{array}{l}\text { "La designación y separación de profesores } \\
\text { universitarios, así como los procedimientos arbitrados } \\
\text { para la selección del cuerpo docente, no admiten, en } \\
\text { principio, revisión judicial por tratarse de cuestiones } \\
\text { propias de las autoridades que tienen a su cargo el } \\
\text { gobierno de la Universidad, salvo en aquellos casos } \\
\text { en que los actos administrativos impugnados en el } \\
\text { ámbito judicial estén afectados por arbitrariedad } \\
\text { manifiesta; afirmación que se sustentaba en las } \\
\text { cláusulas constitucionales que encomiendan a los } \\
\text { poderes políticos del Estado proveer lo conducente al } \\
\text { progreso de la educación y que actualmente encuentra } \\
\text { también fundamento en la autonomía y autarquía de } \\
\text { las universidades nacionales (art. 75, inc. 19)". }\end{array}$ \\
\hline & $\begin{array}{l}\text { Loñ, Félix Roberto } \\
\text { c/UBA - Resols. } \\
859 \text { y } 860 / 98797 \text { y } \\
798 / 98 \\
\text { L. } 461 . \text { XXX- } \\
\text { VI.15/07/2003 } \\
\text { Fallos: } 326: 2374\end{array}$ & $\begin{array}{l}\text { "Corresponde rechazar el agravio fundado en la } \\
\text { discrepancia del recurrente con los criterios de valora- } \\
\text { ción seguidos por el jurado pues ello implica concebir } \\
\text { la revisión judicial con un alcance que llevaría a los } \\
\text { jueces a sustituir los criterios del jurado y a interferir } \\
\text { en ámbitos típicamente académicos, comprendidos } \\
\text { en el marco de la autonomía de las universidades } \\
\text { nacionales y ajenos al control jurisdiccional". }\end{array}$ \\
\hline & $\begin{array}{l}\text { Piaggi, Ana Isabel } \\
\text { c/Universidad } \\
\text { de Buenos Aires } \\
\text { (UBA) Resolución } \\
\text { 3582/2000 } \\
\text { P. } 2708 . \text { XXX- } \\
\text { VIII.29/06/2004 } \\
\text { Fallos: } 327: 2678\end{array}$ & $\begin{array}{l}\text { "La autonomía universitaria no puede ser entendida } \\
\text { de tal manera que implique colocar a las universida- } \\
\text { des, en el plano normativo, al margen de todo control } \\
\text { de constitucionalidad y legalidad, desconociéndose } \\
\text { así el principio general del art. } 116 \text { de la Constitución } \\
\text { Nacional, piedra angular del sistema judicial } \\
\text { argentino". }\end{array}$ \\
\hline
\end{tabular}




\begin{tabular}{|c|c|c|}
\hline \multicolumn{3}{|c|}{ JURISPRUDENCIA DE LA CORTE SUPREMA DE JUSTICIA DE LA NACIÓN } \\
\hline TEMA & CASO & OPINIÓN \\
\hline \multirow[t]{4}{*}{$\begin{array}{l}\text { Régimen } \\
\text { admisión, } \\
\text { perma- } \\
\text { nencia y } \\
\text { promoción } \\
\text { de los } \\
\text { estudiantes }\end{array}$} & $\begin{array}{l}\text { Monges, Analía } \\
\text { M. c/UBA. - resol. } \\
\text { 2314/95 } \\
\text { M. 399. } \\
\text { XXXII.26/12/1996 } \\
\text { Fallos: 319:3148 }\end{array}$ & $\begin{array}{l}\text { "El art. } 50 \text { in fine de la ley } 24.521 \text { mediante el cual el } \\
\text { legislador delegó el ejercicio de su competencia para } \\
\text { fijar planes de admisión que garanticen la capacidad } \\
\text { de los aspirantes, en las facultades pertenecientes a } \\
\text { universidades con más de cincuenta mil estudiantes, } \\
\text { no desconoce sino que afirma la autonomía de las } \\
\text { universidades, ya que el Congreso lo atribuyó a } \\
\text { órganos integrantes de aquéllas". }\end{array}$ \\
\hline & \multirow[t]{2}{*}{$\begin{array}{l}\text { Barsanti, Agustina } \\
\text { c/UBA (Universidad } \\
\text { de Buenos Aires) } \\
\text { Resolución 2314/95 } \\
\text { B 147 } \\
\text { XXXIV30/06/1998 } \\
\text { Fallos: 321:1799 }\end{array}$} & $\begin{array}{l}\text { "El art. } 50 \text { in fine de la ley } 24.521 \text { mediante el cual el } \\
\text { legislador delegó el ejercicio de su competencia para } \\
\text { fijar planes de admisión que garanticen la capacidad } \\
\text { de los aspirantes, en las facultades pertenecientes a } \\
\text { universidades con más cincuenta mil estudiantes, no } \\
\text { desconoce sino que afirma la autonomía de las uni- } \\
\text { versidades, ya que el Congreso lo atribuyó a órganos } \\
\text { integrantes de aquéllas". }\end{array}$ \\
\hline & & $\begin{array}{l}\text { "El art. } 50 \text { de la ley } 24.521 \text {, en cuanto habilita a las } \\
\text { facultades a decidir temas relativos al modo en que } \\
\text { se obtiene y mantiene la condición de estudiante } \\
\text { universitario, ha pretendido establecer una delegación } \\
\text { inconstitucional en favor de un órgano dependiente } \\
\text { de las universidades, lo cual excede las competencias } \\
\text { del poder legislativo y puede ser exclusivamente } \\
\text { dispuesto por el órgano supremo de la estructura } \\
\text { universitaria. (Disidencias de los Dres. Carlos S. Fayt y } \\
\text { Gustavo A. Bossert)". }\end{array}$ \\
\hline & $\begin{array}{l}\text { Universidad } \\
\text { Nacional de } \\
\text { Córdoba (doctor } \\
\text { Eduardo Humberto } \\
\text { Staricco - rector) } \\
\text { c/Estado Nacional } \\
\text {-declaración de } \\
\text { inconstitucionali- } \\
\text { dad- sumario. } \\
\text { U } 2 \\
\text { XXXIII27/05/1999 } \\
\text { Fallos: 322:919 }\end{array}$ & $\begin{array}{l}\text { "El art. } 50 \text { in fine de la ley } 24.521 \text { concreta una } \\
\text { delegación en favor de un órgano dependiente } \\
\text { de las universidades que es inconstitucional por } \\
\text { cuanto limita sustancialmente una atribución que, por } \\
\text { mandato del poder constituyente, corresponde a la } \\
\text { universidad como centro unitario (Disidencia parcial } \\
\text { del Dr. Augusto César Belluscio)". }\end{array}$ \\
\hline
\end{tabular}




\begin{tabular}{|l|l|l|}
\hline \multicolumn{2}{|c|}{ JURISPRUDENCIA DE LA CORTE SUPREMA DE JUSTICIA DE LA NACIÓN } \\
\hline TEMA & \multicolumn{1}{|c|}{ CASO } & \multicolumn{1}{c|}{ OPINIÓN } \\
\hline \multirow{2}{*}{} & $\begin{array}{l}\text { Brito, Guillermo } \\
\text { Octavio y otros } \\
\text { c/Universidad Na- } \\
\text { cional de Tucumán. } \\
\text { B. 405. XXX- } \\
\text { VI.24/02/2004 } \\
\text { to en el art. 75, inc. 19, de la Constitución Nacional } \\
\text { (Disidencia parcial del Dr. Carlos S. Fayt)". }\end{array}$ & $\begin{array}{l}\text { "En ejercicio de la competencia atribuida por el } \\
\text { art. 75, inc. 19, de la Constitución Nacional, el } \\
\text { Congreso dictó la ley 24.521, cuyo art. 29 define, en } \\
\text { general, la autonomía académica e institucional de las } \\
\text { universidades al expresar que comprende, entre otras } \\
\text { atribuciones, la de establecer el régimen de admisión, } \\
\text { permanencia y promoción de los estudiantes (inc. j) } \\
\text { yel art. } 50 \text { in fine prescribe que dicho régimen será } \\
\text { definido por cada facultad cuando las universidades } \\
\text { cuenten con más de cincuenta mil estudiantes. -Del } \\
\text { dictamen de la Procuración General, al que remitió la } \\
\text { Corte Suprema-". }\end{array}$ \\
\hline
\end{tabular}

\section{Conclusiones}

En este trabajo propuse la distinción entre el criterio jerárquico y el de competencias, para comprender adecuadamente las distintas relaciones que pueden suscitarse entre normas creadas por distintos poderes, órganos y entes. Los conflictos analizados no se resuelven por aplicación del principio jerárquico, haciendo prevalecer automáticamente la ley sobre el estatuto. La ley no puede entrometerse en asuntos que hacen a la esencia de la autonomía universitaria. Por esta razón, se debe recurrir al principio de competencia para arribar a una solución jurídica congruente con las tareas que la $\mathrm{CN}$ le encomienda tanto al Congreso Nacional como a las universidades nacionales. De igual modo, se tiene que utilizar el criterio de especialidad para identificar al titular de la atribución regulatoria.

En cuanto al primer conflicto planteado, por un lado, el régimen jubilatorio es competencia y especialidad del Congreso Nacional y, por otro, el régimen de permanencia de los profesores es competencia y especialidad de las universidades 
nacionales. La seguridad social es tarea del Congreso Nacional, ya que así lo mandan los artículos 14 bis y 75, inciso 12, CN. En la misma línea se encuentra el artículo 75, inciso $23, \mathrm{CN}$, que obliga al Congreso Nacional a adoptar medidas de acción positiva que incluyan a las personas con discapacidad.

La autonomía académica plasmada en la CN y reconocida por la ley de Educación Superior opera como garantía para el cumplimiento de las misiones primordiales de las universidades nacionales. En esa óptica, las universidades regulan el acceso y la permanencia docente, estableciendo el régimen de concursos, con el afán de cumplir con las bases de su estatuto.

En pocas palabras, se configura la inconstitucionalidad de la Ley 26.508, en virtud de que el Congreso Nacional actuó fuera del marco de su competencia, al regular cuestiones que exceden los beneficios de la seguridad social y que guardan relación con el régimen de permanencia docente, el cual es facultad privativa de las Universidades Nacionales. Sobre este tema, es dable recordar el Manifiesto Liminar de la Reforma Universitaria de 1918, por su evidente actualidad y aplicación al caso analizado: "Nuestro régimen universitario -aún el más reciente- es anacrónico. Está fundado sobre una especie de derecho divino; el derecho divino del profesorado universitario. Se crea a sí mismo. En él nace y en él muere".

En relación con la segunda problemática estudiada, la implementación de políticas públicas de protección de los discapacitados es competencia y especialidad del Congreso Nacional y las universidades nacionales deben aplicar esa legislación. Como he señalado anteriormente, el Congreso Nacional está obligado por la $\mathrm{CN}$ y los tratados de derechos humanos con jerarquía constitucional a diseñar políticas de inclusión y no discriminación para las personas con discapacidad. La implementación de esa legislación es compatible con la autonomía de las universidades, toda vez que no se vincula con su especialidad o razón de ser.

La posibilidad de que las universidades se den sus propias normas en lo institucional, lo político, lo administrativo y lo 
académico no las habilitan a pergeñar un sistema de protección propio e independiente de los derechos fundamentales, que nada tiene que ver con los fines para los cuales la CN las invistió de autonomía. La tarea de reglamentación y efectivización de los derechos de raíz constitucional o convencional está asignada, en primer término, al Congreso Nacional, en virtud de lo cual la oportunidad, el mérito o la conveniencia de las decisiones del legislador no afectan el núcleo esencial de la autonomía.

Ello no impide que las universidades diseñen políticas coadyuvantes de protección de los derechos. En este sentido, cabe destacar que la Facultad de Derecho de la Universidad de Buenos Aires mediante Resolución (D) no 5110/04, del 16 de marzo de 2004, creó el "Programa Universidad y Discapacidad", cuya misión primordial es cooperar en la integración de personas con discapacidad. Del mismo modo, el Consejo Superior de la Universidad de Buenos Aires, mediante Resoluciones (CS) $\mathrm{n}^{\mathrm{o}} 154 / 02$ y 1859/03, dispuso la creación de una comisión de estudio y un área permanente para la atención de la problemática de las personas con discapacidad. Luego de ello, el Rector dictó la Resolución 339/07, del 25 de abril de 2007, mediante la cual se creó el "Programa Discapacidad y Universidad" con las siguientes funciones:

a) Promover estudios que favorezcan la inclusión plena de las personas con discapacidad y proponer medidas para eliminar todas las formas de discriminación (...); b) Trabajar para lograr la plena accesibilidad física, comunicacional, cultural y pedagógica en todos los ámbitos de la universidad y c) Favorecer la concientización de todos los miembros de la comunidad universitaria, en relación con los derechos y necesidades de las personas con discapacidad y lograr así su plena integración en la vida académica.

Ambos programas son un buen ejemplo de políticas creadas por la UBA que no se entrometen en atribuciones propias del Congreso Nacional y que contribuyen a la realización del catálogo de derechos fundamentales. Asimismo, este tipo de iniciativas se 
enmarcan dentro del principio reformista de la extensión universitaria y en la función social que debe cumplir la universidad.

El abanico de temas involucrados con la educación superior es extenso y complejo, razón por la cual no es tarea sencilla delimitar las competencias del Congreso Nacional y de las universidades nacionales. Un análisis minucioso de la Ley de Educación Superior arrojaría como resultado que parte de su articulado se entromete en asuntos que hacen a la esencia de la autonomía de las universidades, mientras que otras disposiciones no lo hacen, puesto que su dictado es la consecuencia natural del ejercicio de potestades inherentes del Congreso Nacional.

El legislador puede y debe regular las atribuciones de las instituciones universitarias con el afán de lograr el progreso de la Nación, pero no puede ignorar los principios esenciales de la autonomía universitaria. Estos principios, indiscutiblemente, están vinculados a la Reforma Universitaria de 1918, toda vez que son su fruto y conforman el núcleo esencial del quehacer universitario. Los postulados de aquella reforma definen el contenido básico de la autonomía universitaria y deben ser respetados por la legislación. El Congreso no puede regular las materias elementales de la vida universitaria.

En suma, por una parte, el Congreso puede establecer políticas públicas para la educación superior, pero esas líneas de acción, que son discrecionales, no deben afectar el reducto de competencias esenciales que posibilitan las misiones constitucionales de las universidades nacionales. Por otra parte, el Poder Ejecutivo debe ser extremadamente cauteloso en el uso de sus atribuciones reglamentarias, debido a que el poder de reglamentar los detalles de las leyes de la educación superior es tarea de las universidades.

En conclusión, la educación superior requiere del trabajo articulado del Congreso Nacional -en cuanto poder representativo de la sociedad-y de las universidades nacionales -en su carácter de institución autónoma del gobierno de turno- en un diálogo permanente y constructivo que respete e identifique las competencias que la $\mathrm{CN}$ le asigna a cada uno en sus roles y funciones. 


\section{Bibliografía}

\section{Doctrina}

Alterini, Atilio Aníbal, La universidad pública en un proyecto de nación, Buenos Aires, La Ley, 2005.

Átvarez, Gonzalo y Scioscioli, Sebastián, "Las bases constitucionales de la educación argentina a la luz de la reforma constitucional de 1994", en Bernal, Marcelo, Pízzolo, Calogero y Rossetti, Andrés (Coordinadores), iQue veinte años no es nada!: un análisis crítico a veinte años de la reforma constitucional de 1994 en Argentina, Ciudad Autónoma de Buenos Aires, Eudeba, 2015.

Balbín, Carlos F., Curso de Derecho Administrativo, Buenos Aires, La Ley, 2007.

Bidart Campos, Germán J., Manual de la Constitución Reformada, t. 1, Buenos Aires, Ediar, 1996.

Dalla Vía, Alberto R., Manual de Derecho Constitucional, Buenos Aires, Abeledo Perrot, 2009.

Ferreyra, Raúl Gustavo: Fundamentos Constitucionales, Buenos Aires, Ediar, 2013.

-, Notas sobre Derecho Constitucional y garantías, Buenos Aires, Ediar, 2016.

Finocchiaro, Alejandro, El mito reformista, Ciudad Autónoma de Buenos Aires, Eudeba, 2018.

Gelu, María Angélica, Constitución de la Nación Argentina: comentada y concordada, Buenos Aires, La Ley, 2005.

Luchilo, Lucas, "El gobierno de la universidad reformista: los debates para el Estatuto de la Universidad de Buenos Aires (1958)", en Albornoz, Mario y Crespo, Manuel (Compiladores), La universidad reformada: hacia el centenario de la reforma universitaria de 1918, Ciudad Autónoma de Buenos Aires, Eudeba, 2017.

Luna, Félix, Yrigoyen, Buenos Aires, Editorial de Belgrano, 1982.

Marienhoff, Miguel S., Tratado de Derecho Administrativo, t .1, Buenos Aires, Abeledo-Perrot, 2011.

Nino, Carlos Santiago, Introducción al análisis del derecho, Buenos Aires, Astrea, 1998. 
Quiroga Lavié, Humberto, "La autonomía universitaria”, en La Ley, t. 1987-B.

Stubrin, Adolfo, "La Reforma de 1918: el hecho crucial para la configuración universitaria de la Argentina”, en Albornoz, Mario y Crespo, Manuel (Compiladores), La universidad reformada: hacia el centenario de la reforma universitaria de 1918, Ciudad Autónoma de Buenos Aires, Eudeba, 2017.

\section{Jurisprudencia de la CSJN}

"S.A. Martín y Cía. Ltda. v. Nación Argentina" (1963), Fallos: 257:99. "Universidad Nacional de Buenos Aires c/Estado Nacional (PEN) s/inconstitucionalidad de decreto" (1991), Fallos: 314:570.

"Ekmekdjián, Miguel Ángel c/Sofovich, Gerardo y otros" (1992), Fallos: 315:1492.

"Monges, Analía M. c/UBA (Universidad de Buenos Aires) Resolución 2314/95" (1996), Fallos: 319:3148.

"Mocchiutti, Juan c/ UNC s/contencioso administrativo" (1997), Fallos: 335:1655.

"Barsanti, Agustina c/ UBA (Universidad de Buenos Aires) Resolución 2314/95" (1998), Fallos: 321:1799.

"Estado Nacional (Ministerio de Cultura y Educación) c/Universidad Nacional de Lujan s/ Aplicación Ley 24521" (1999), Fallos: 322:842.

"Universidad Nacional de Córdoba (doctor Eduardo Humberto Staricco - rector) c/Estado Nacional - declaración de inconstitucionalidad - sumario" (1999), Fallos: 322:919.

"González de Delgado, Cristina y otros c/Universidad Nacional de Córdoba" (2000), Fallos: 323:2659.

"Tandecarz, Juana Sara y otros c/Universidad de Buenos Aires" (2002), Fallos: 325:1676.

"Universidad Nacional de Mar del Plata c/ Banco Nación Argentina s/ daños y perjuicios" (2003), Fallos: 326:1355.

"Molina, José Luis c/Universidad Nacional de Catamarca" (2003), Fallos: 326:1389.

"Loñ, Félix Roberto c/UBA - Resols. 859 y 860/98 y 798/98" (2003), Fallos: 326:2374. 
"Brito, Guillermo Octavio y otros c/Universidad Nacional de Tucumán" (2004), Fallos: 327:227.

"Piaggi, Ana Isabel c/Universidad de Buenos Aires (UBA) Resolución 3582/2000" (2004), Fallos: 327:2678.

"Estado Nacional - Ministerio de Cultura y Educación c/Universidad Nacional de General Sarmiento s/ Recurso" (2008).

"Ministerio de Cultura y Educación - Estado Nacional s/art. 34 de la ley 24.521" (2008), Fallos: 331:1123.

"Universidad Nacional de Córdoba c/Estado Nacional - Ministerio de Trabajo y S.S. s/Acción Declarativa Art. 322 CPCC” (2010), Fallos: 333:1951.

"Franchini, Rafael Luis -hoy Jerosimich Margarita c/Resol. No 320/3 del Consejo Sup. De la UNNE s/ Recurso de Apelación art. 32 de la Ley 24.521" (2012), Fallos: 335:1655.

"Ministerio de Educación de la Nación c/Universidad Nac. Del Noroeste de la Prov. De Bs. As. s/Recurso Administrativo Directo" (2014).

"Universidad Nacional de Rosario c/Entre Ríos, Provincia de s/Amparo (Daño Ambiental) (2014), Fallos: 337:1447.

"Ministerio de Cultura y Educación de la Nación c/Universidad Nacional de la Plata s/Inf. Ley 24.521 art. 34" (2016), Fallos: 339:115.

"Ryser, Walter Adolfo c/Universidad Nacional de Catamarca s/Apelación art. 32 Ley 24.521" (2017), Fallos: 340:614.

“Biasizo, Rogelio José c/UTN s/Empleo Público” (2017), Fallos: 340:983.

\section{Otros documentos}

Universidad de Buenos Aires, "Aportes de la Universidad de Buenos Aires hacia la Conferencia Regional de Educación Superior de América Latina y el Caribe 2018", aprobado mediante Resolución (CS) 345/08, del 25 de abril del 2018. 